\title{
Investigation of carbon dioxide photoreduction process in a laboratory-scale photoreactor by computational fluid dynamic and reaction kinetic modeling
}

\author{
Xuesong Lu, Xiaojiao Luo, Warren A. Thompson, Jeannie Z.Y. Tan, M. Mercedes Maroto-Valer (ه) \\ Research Centre for Carbon Solutions, School of Engineering and Physical Sciences, Heriot-Watt University, Edinburgh EH14 4AS, UK
}

(C) The Author(s) 2021. This article is published with open access at link.springer.com and journal.hep.com.cn

\begin{abstract}
The production of solar fuels via the photoreduction of carbon dioxide to methane by titanium oxide is a promising process to control greenhouse gas emissions and provide alternative renewable fuels. Although several reaction mechanisms have been proposed, the detailed steps are still ambiguous, and the limiting factors are not well defined. To improve our understanding of the mechanisms of carbon dioxide photoreduction, a multiphysics model was developed using COMSOL. The novelty of this work is the computational fluid dynamic model combined with the novel carbon dioxide photoreduction intrinsic reaction kinetic model, which was built based on three-steps, namely gas adsorption, surface reactions and desorption, while the ultraviolet light intensity distribution was simulated by the Gaussian distribution model and Beer-Lambert model. The carbon dioxide photoreduction process conducted in a laboratoryscale reactor under different carbon dioxide and water moisture partial pressures was then modeled based on the intrinsic kinetic model. It was found that the simulation results for methane, carbon monoxide and hydrogen yield match the experiments in the concentration range of $10^{-4} \mathrm{~mol} \cdot \mathrm{m}^{-3}$ at the low carbon dioxide and water moisture partial pressure. Finally, the factors of adsorption site concentration, adsorption equilibrium constant, ultraviolet light intensity and temperature were evaluated.
\end{abstract}

Keywords carbon dioxide photoreduction, computational fluid dynamic simulation, kinetic model, Langmuir adsorption

Received March 29, 2021; accepted July 19, 2021

E-mail: M.Maroto-Valer@hw.ac.uk

\section{Introduction}

Atmospheric carbon dioxide $\left(\mathrm{CO}_{2}\right)$ mainly from combustion of fossil fuel is one of the major greenhouse gases and contributes about $60 \%$ to global warming [1]. To mitigate $\mathrm{CO}_{2}$ emissions, the usage of fossil fuels should be decreased as well as deploying $\mathrm{CO}_{2}$ capture, utilization and storage strategies. $\mathrm{CO}_{2}$ utilization via photoreduction to methane $\left(\mathrm{CH}_{4}\right)$ is a promising method to produce solar fuels aiming at dealing with the problems of insufficiency of sustainable energy and reduction of $\mathrm{CO}_{2}$ emissions $[2,3]$.

However, the main obstacle for the $\mathrm{CO}_{2}$ photoreduction to $\mathrm{CH}_{4}$ process to be commercialised is its low conversion rate [4]. To address this challenge, understanding the mechanism and reaction kinetics is crucial for the improvement of the reaction efficiency [5]. The heterogeneous $\mathrm{CO}_{2}$ photoreduction process includes the separation and recombination of electron-hole pairs in the semiconductor (photocatalyst), the gas adsorption and desorption on the surface of the photocatalyst, the electron and hole trapping reactions and the radical propagation reactions [6]. For the widely used photocatalyst $\mathrm{TiO}_{2}$, Qian et al. [7] reviewed charge carrier trapping, recombination and transfer, whereas Vorontsov et al. [8] reviewed its surface chemistry. In general, most of the kinetic models proposed for $\mathrm{CO}_{2}$ photoreduction were based on the Langmuir-Hinshelwood equation and assumed adsorption and reaction as a one-step process [9]. For instance, Tahir and Amin [10] constructed the reaction kinetics of $\mathrm{CO}_{2}$ photoreduction in a microchannel monolith photoreactor using the Langmuir-Hinshelwood reaction kinetic model. To account for apparent photocatalyst deactivation under continuous flow, Thompson et al. [11] introduced the Weibull possibility density function into the kinetic equation. Meanwhile, Marczewski [12] proposed a simple and easy integrated kinetic Langmuir model to analyze the 
comprehensive reaction process. Bloh [13] built a kinetic model based on the generation of reactive surface sites, recombination of charge-carrier counterpart and charge transfer to the target substrate.

Computational fluid dynamic (CFD) modeling combining reaction kinetics is an effective tool to ascertain the reaction process [14]. Understanding the interactions between physical behavior and chemical reaction mechanism helps to determine the key parameters controlling the whole process and guides the future reactor design and scale-up. CFD studies have been reported to model different photoreactors, as discussed here: 1) A slurry bed photoreactor with ultraviolet (UV) lamps was used by Chu et al. [15] to model a new type of $\mathrm{CO}_{2}$ photoreduction reactor, namely a twin reactor. 2) A packed bed or monolith reactor with optical fibers was modeled by Chen et al. [16] to investigate $\mathrm{CO}_{2}$ photoreduction. 3) A thin-film flatbed reactor was modeled by Verbruggen et al. [17] for the degradation of gaseous acetaldehyde. However, this type of thin-film photoreactor has not been simulated for $\mathrm{CO}_{2}$ photoreduction to $\mathrm{CH}_{4}$.

For investigating reaction kinetics of $\mathrm{CO}_{2}$ photoreduction in single gas phase, the thin-film flatbed with simple reactor configuration and simple mass transfer process is preferred because it is less affected by relatively complex mass transfer process than the slurry bed or packed bed [9]. For example, for the standardisation in testing conditions to make the assessment of process parameters, Olivo et al. [18] investigated the irradiance and reaction parameters of $\mathrm{CO}_{2}$ photoreduction on production of $\mathrm{CH}_{4}$ in two thin-film photoreactors. Previously, the first-order or pseudo firstorder Langmuir-Hinshelwood model was applied for the reaction kinetics [10], while for the radiation model, the line source spherical emission was employed for describing the radiation field neglecting the attenuation along the $z$-direction [19]. However, the simplification of reaction kinetics and description of the radiation field may lose some details of the whole reaction process, e.g., nonlinear reaction process and reaction contribution by the thin film along the $z$-direction besides the surface along the $x$ - and $y$ directions.

The purpose of this work is to understand the mechanism of $\mathrm{CO}_{2}$ photoreduction using Langmuir theory and surface reaction. The novelty is that this work uniquely develops and combines a three-step intrinsic kinetic model that included adsorption, surface reactions and desorption, as well as a unique irradiation model that considered the depth of the thin film in combination of the Gaussian equation and the Beer-Lambert equation. Hence, the kinetic model, which was developed in this study, used CFD modeling as an effective tool to understand and differentiate flow behavior and surface reactions. This is used for the first time in modeling $\mathrm{CO}_{2}$ photoreduction process. By using this unique approach, it is possible to improve the whole $\mathrm{CO}_{2}$ photoreduction process as well as provide guidance for photoreactor design. This approach also allowed to explore the dominant parameters influencing the $\mathrm{CO}_{2}$ photoreduction and guide experimental studies.

\section{Simulation of $\mathrm{CO}_{2}$ photoreduction}

\section{1 $\mathrm{CO}_{2}$ photoreduction in a thin-film reactor}

In this work, the photoreactor dimensions and $\mathrm{CO}_{2}$ photoreduction conditions for simulation originate from published work [11]. The schematic diagram of the photoreactor is shown in Fig. 1. The diameter and height of the reactor are 50 and $1 \mathrm{~mm}$, respectively. The diameters of the gas inlet and outlet are 0.8 and $1.2 \mathrm{~mm}$, respectively. The photocatalyst support mesh has dimensions of $25 \mathrm{~mm}$ $\times 40 \mathrm{~mm}$. The thickness of the catalyst thin film is $0.2 \mathrm{~mm}$. The gas mixture of $\mathrm{Ar}, \mathrm{CO}_{2}$ and water moisture $\left(\mathrm{H}_{2} \mathrm{O}\right)$ enters the reactor at a flow rate of $0.35 \mathrm{~mL} \cdot \mathrm{min}^{-1}$ and the product mixture of $\mathrm{H}_{2}, \mathrm{CO}$ and $\mathrm{CH}_{4}$ with unreacted gases flows out of the reactor into the gas chromatograph (GC). The whole reactor was placed on the hotplate and the temperature was controlled at $314.15 \mathrm{~K}$. The intensity of the UV light (wavelength $365 \mathrm{~nm}$ ) at the end of the optical fiber is $400 \mathrm{~mW} \cdot \mathrm{cm}^{-2}$. The average UV light intensity on the surface of the photocatalyst film is $160 \mathrm{~W} \cdot \mathrm{m}^{-2}$.

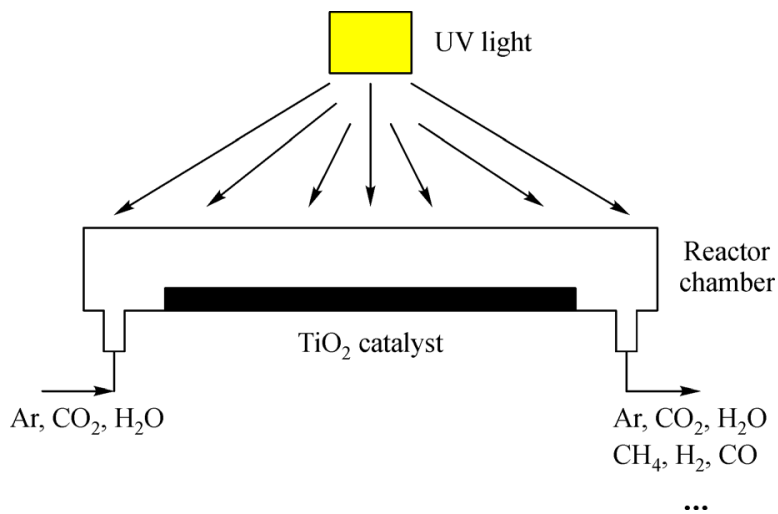

Fig. 1 Schematic diagram of the studied $\mathrm{CO}_{2}$ photoreduction reactor.

Thompson et al. [9] pointed out that the partial pressures of both $\mathrm{CO}_{2}$ and $\mathrm{H}_{2} \mathrm{O}$ are likely to influence the reaction rate. Therefore, the experiments were divided into two groups: 1) $\mathrm{CO}_{2}$ partial pressure from 25.72 to $98.38 \mathrm{kPa}$; 2) $\mathrm{H}_{2} \mathrm{O}$ partial pressure from 2.66 to $6.64 \mathrm{kPa}$. The detailed experimental conditions are presented in Table 1.

\section{2 $\mathrm{CO}_{2}$ photoreduction mechanism}

Kočí et al. [20] and Ji and Luo [21] studied the mechanism of $\mathrm{CO}_{2}$ photoreduction to $\mathrm{CH}_{4}$ on the anatase $\mathrm{TiO}_{2}$ surface by the first-principles calculation on the thermodynami- 
Table 1 Experimental conditions

\begin{tabular}{lcccccc}
\hline Experiment No. & Experiment code ${ }^{\text {a) }}$ & $\begin{array}{c}\text { Photocatalyst } \\
\text { loading/mg }\end{array}$ & $\begin{array}{c}\mathrm{CO}_{2} \text { partial pressure } \\
/ \mathrm{kPa}\end{array}$ & $\begin{array}{c}\text { Ar partial pressure } \\
/ \mathrm{kPa}\end{array}$ & $\begin{array}{c}\mathrm{H}_{2} \mathrm{O} \text { partial pressure } \\
/ \mathrm{kPa}\end{array}$ & $\begin{array}{c}\text { Flow rate } \\
/\left(\times 10^{-9} \mathrm{~m}^{3} \cdot \mathrm{s}^{-1}\right)\end{array}$ \\
\hline 1 & $\mathrm{PCO}_{2} \mathrm{H}$ & 83.0 & 25.72 & 74.30 & 2.66 & 5.9883 \\
2 & $\mathrm{PCO}_{2} \mathrm{I}$ & 83.0 & 48.44 & 48.44 & 2.74 & 6.0030 \\
3 & $\mathrm{PCO}_{2} \mathrm{~L}$ & 83.0 & 98.38 & 0 & 2.62 & 5.9883 \\
5 & $\mathrm{PH}_{2} \mathrm{OH}$ & 90.6 & 25.72 & 74.30 & 2.66 & 5.9886 \\
6 & $\mathrm{PH}_{2} \mathrm{OI}$ & 90.6 & 25.50 & 73.67 & 3.47 & 6.0367 \\
\hline
\end{tabular}

a) H, I and L stand for relatively high, intermediate and low pressure, respectively, of Ar.

cally feasible formaldehyde (HCHO) pathway. They showed that $\mathrm{CO}_{2}$ photoreduction will be more efficient when the formation of $\mathrm{CO}$ is preferred if $\mathrm{CO}$ instead of formic acid $(\mathrm{HCOOH})$ during the reduction process. Thompson et al.'s work [11] showed that CO is one of dominant intermediate products, and thus, in this work we chose and treated the potential $\mathrm{CO}$ pathway as the main reaction route for $\mathrm{CO}_{2}$ photoreduction to $\mathrm{CH}_{4}$. To further simplify the reaction route, the intermediate products of $\mathrm{HCHO}$ and methanol $\left(\mathrm{CH}_{3} \mathrm{OH}\right)$ are not considered in our simulation and $\mathrm{CO}$ directly generates $\mathrm{CH}_{4}$.

\subsection{Governing equations}

In this work, the $\mathrm{CO}_{2}$ photoreduction takes place in a onephase gas flow reactor, where the flow is in the laminar regime $\left(\mathrm{Re}_{\mathrm{in}}<0.1\right)$. The photocatalyst thin film is treated as a surface with the size of $40 \mathrm{~mm} \times 25 \mathrm{~mm}$. The assumptions employed for the photoreduction reactor include: 1) the gas flow is in the steady-state; 2) the gas is incompressible; 3 ) the gas density and viscosity are constant during the whole process and are obtained by the mixture mole ratio of $\mathrm{Ar}, \mathrm{CO}_{2}$ and $\mathrm{H}_{2} \mathrm{O}$. Because the generated quantity of $\mathrm{CH}_{4}, \mathrm{CO}$ and $\mathrm{H}_{2}$ with concentration around $10^{-4} \mathrm{~mol} \cdot \mathrm{m}^{-3}$ is much smaller than that of $\mathrm{Ar}, \mathrm{CO}_{2}$ and $\mathrm{H}_{2} \mathrm{O}$ with concentration around $1-20 \mathrm{~mol} \cdot \mathrm{m}^{-3}$, we do not consider the change of gas density with the studied reactions; 4) the gas enters the reactor at the inlet with a uniform constant velocity distribution; 5) the reactor wall is adiabatic; 6) the heating caused by the UV lighting is negligible; 7) the photocatalyst is always active during the process and the deactivation of photocatalysts is not considered in this work; 8) the hole and electron generation and recombination activated by the UV lighting are very fast and do not influence the hole and electron trapping reactions; 9) the temperature distribution is uniform.

The governing equations are as follows:

(1) Mass equation

$$
\rho \nabla \cdot(\boldsymbol{u})=m_{\mathrm{s}},
$$

where $\rho$ is the density; $u$ is the velocity; $m_{\mathrm{s}}$ is the mass source.
(2) Momentum equation

$$
\rho(u \cdot \nabla) u=\nabla \cdot\left[-p+\mu\left(\nabla \boldsymbol{u}+(\nabla \boldsymbol{u})^{\mathrm{T}}\right)\right],
$$

where $p$ is the pressure; $\mu$ is the kinematic viscosity.

(3) Species equation

$$
\nabla \cdot\left(-D_{i} \nabla c_{i}\right)+\boldsymbol{u} \cdot \nabla c_{i}=R_{i},
$$

where $D_{i}$ is the diffusivity; $c_{i}$ is the mole concentration; $R_{i}$ is the reaction mass source.

\subsection{Langmuir adsorption}

The mass transfer between the bulk flow and photocatalyst surface is described by the Langmuir adsorption model. The gas adsorption and desorption are reversible and the adsorption of gas species on the surface is related to the gas partial pressure and adsorption sites (S). The adsorption steps are shown in the following reactions.

$$
\begin{gathered}
\mathrm{Ar}+\mathrm{S} \rightleftarrows \mathrm{S}-\mathrm{Ar} \\
\mathrm{CO}_{2}+\mathrm{S} \rightleftarrows \mathrm{S}-\mathrm{CO}_{2} \\
\mathrm{H}_{2} \mathrm{O}+\mathrm{S} \rightleftarrows \mathrm{S}-\mathrm{H}_{2} \mathrm{O} \\
\mathrm{H}_{2}+\mathrm{S} \rightleftarrows \mathrm{S}-\mathrm{H}_{2} \\
\mathrm{CO}+\mathrm{S} \rightleftarrows \mathrm{S}-\mathrm{CO} \\
\mathrm{O}_{2}+\mathrm{S} \rightleftarrows \mathrm{S}-\mathrm{O}_{2} \\
\mathrm{CH}_{4}+\mathrm{S} \rightleftarrows \mathrm{S}-\mathrm{CH}_{4}
\end{gathered}
$$

The adsorption rate is

$$
r_{\mathrm{ad}}=k_{\mathrm{ad}} p_{i}[\mathrm{~S}]
$$

where $r_{\mathrm{ad}}$ is the adsorption rate; $k_{\mathrm{ad}}$ is the adsorption rate constant; $p_{i}$ is the partial pressure; $[\mathrm{S}]$ is the bare site density. The desorption rate is

$$
r_{\mathrm{de}}=k_{\mathrm{de}}\left[c_{\mathrm{ad}}\right]
$$


where $r_{\mathrm{de}}$ is the desorption rate; $k_{\mathrm{de}}$ is the desorption rate constant; $\left[c_{\mathrm{ad}}\right]$ is the adsorbed concentration.

If the desorption is described by the Arrhenius model, the kinetic constant is

$$
k_{\mathrm{de}}=A_{\mathrm{d}} \mathrm{e}^{-\frac{E_{\mathrm{d}}}{\mathrm{R} T}},
$$

where $A_{\mathrm{d}}$ is the frequency factor; $\mathrm{R}$ is the gas constant. $E_{\mathrm{d}}$ is the heat of desorption [22].

$$
E_{\mathrm{d}}=-\Delta H_{\mathrm{ad}}-\frac{1}{2} \mathrm{R} T,
$$

where $\Delta H_{\mathrm{ad}}$ is the adsorption enthalpy. The adsorption equilibrium constant is

$$
K_{\mathrm{eq}}=\frac{k_{\mathrm{ad}}}{k_{\mathrm{de}}},
$$

where $K_{\text {eq }}$ is the adsorption equilibrium constant.

\subsection{UV lighting}

In this work, the irradiation model neglects the absorption, scattering or emission of radiation by the gaseous media in the reactor, which follows the literature [19].

The UV light intensity distribution along the $x, y$ directions is described by the Gaussian distribution model. The light intensity distribution is

$$
I_{(r)}=I_{(0)} \mathrm{e}^{-\frac{2 r^{2}}{\omega_{0}^{2}}}
$$

where $I$ is the light intensity; $r$ is the radius and $\omega_{0}$ is the beam radius.

The radiative transport equation (RTE, Eq. (17)) comprising the light absorption, extinction, and scattering is used to model the UV light intensity along the thin-film thickness. In this work, the UV light radiative intensity is dominated by scattering and extinction [23]:

$$
\begin{aligned}
\Omega \cdot \nabla I(\Omega)= & \kappa I_{\mathrm{b}}(T)-\beta I(\Omega) \\
& +\frac{\sigma_{\mathrm{s}}}{4 \pi} \int I\left(\Omega^{\prime}\right) \phi\left(\Omega^{\prime}, \Omega\right) \mathrm{d} \Omega^{\prime},
\end{aligned}
$$

where, $I(\Omega)$ is the radiative intensity at a given position following the $\Omega$ direction; $\kappa$, absorption coefficient; $\beta$, extinction coefficient; $\sigma_{\mathrm{s}}$, scattering coefficient.

Finally, the UV light intensity distribution along the $z$-direction can be simply described by the Beer-Lambert model. The light intensity distribution is

$$
I_{(z)}=I_{1} \mathrm{e}^{-\mu_{\mathrm{L}} z},
$$

where $\mu_{\mathrm{L}}$ is the attenuation coefficient; $z$ is the depth of lighting in the object.

Due to the attenuation of light intensity, we divided the film into ten layers. To easily perform the simulation, the real three-dimensional photocatalyst thin film in this work was considered as a $\mathrm{XY}$ plate surface to overcome the difficulty of meshing, but this causes the XY plate surface area is less than the real area of the thin film. As gas adsorption, reaction and desorption directly depend on the number of active sites on the surface, here we assume all the adsorption sites in the real thin film are distributed uniformly on the XY plate surface in the physical model. The light intensity for the surface reaction model is

$$
\begin{aligned}
I \cdot \frac{A_{\mathrm{e}}}{A_{\mathrm{t}}}= & I_{1.0} \cdot \frac{z_{1.0}}{z_{\mathrm{t}}}+I_{0.9} \cdot \frac{z_{0.9}}{z_{\mathrm{t}}}+I_{0.8} \cdot \frac{z_{0.8}}{z_{\mathrm{t}}}+\cdots \\
& +I_{0.1} \cdot \frac{z_{0.1}}{z_{\mathrm{t}}} .
\end{aligned}
$$

\subsection{Surface reactions}

From prior theoretical [21] and experimental investigations [11], $\mathrm{CO}$ is the preferred intermediate of $\mathrm{CO}_{2}$ photoreduction on the $\mathrm{P} 25 \mathrm{TiO}_{2}$ thin film. Therefore, we consider the $\mathrm{CO}_{2}$ photoreduction mechanism described in Section 2.2 [21] as $\mathrm{CO}_{2} \rightarrow \mathrm{CO} \rightarrow \mathrm{HCHO} \rightarrow \mathrm{CH}_{3} \mathrm{OH} \rightarrow \mathrm{CH}_{4}$ and simplification of the intermediate reactions between $\mathrm{CO}$ and $\mathrm{CH}_{3} \mathrm{OH}$ as $\mathrm{CO}$ directly to generate $\mathrm{CH}_{4}$, where the surface reactions are shown as follow:

$$
\begin{gathered}
2 \mathrm{H}_{2} \mathrm{O}=2 \mathrm{H}_{2}+\mathrm{O}_{2} \\
\mathrm{CO}_{2}+\mathrm{H}_{2}=\mathrm{CO}+\mathrm{H}_{2} \mathrm{O} \\
\mathrm{CO}+3 \mathrm{H}_{2}=\mathrm{CH}_{4}+\mathrm{H}_{2} \mathrm{O}
\end{gathered}
$$

The reaction rate is

$$
r_{\mathrm{r}}=k_{\mathrm{r}} I \frac{A_{\mathrm{e}}}{A_{\mathrm{t}}}\left[c_{i}\right]^{m}\left[c_{j}\right]^{n},
$$

where $r_{\mathrm{r}}$ is the reaction rate; $k_{\mathrm{r}}$ is the reaction rate constant; $A_{\mathrm{e}}$ is the effective lighting area; $A_{\mathrm{t}}$ is the total area of the photocatalyst; $m, n$ is the order of the reaction. The reaction constant is

$$
k_{\mathrm{r}}=A_{\mathrm{r}} \mathrm{e}^{-\frac{E_{\mathrm{a}}}{\mathrm{R} T}},
$$

where $A_{\mathrm{r}}$ is the frequency factor; $E_{\mathrm{a}}$ is the activation energy.

\subsection{Simulation method}

The simulation was performed using COMSOL version 5.2a. The three modules, including laminar flow, transport of diluted species and general form boundary partial differential equations (PDE) were employed. The NewtonRaphson method is used for discretization of all the differential equations. For laminar flow, P2 (velocity) + P1 (pressure) is used. For species dilute transport and boundary, the quadratic method is used. The simulation 
process has two consecutive steps: first, the fully coupled velocity, and pressure are solved; followed by the fully coupled species transport and surface reactions. For the nonlinear iterative method, the flexible generalized minimal residual method is used. The relative tolerance is 0.001 . The factor in error estimate is 80 . The scaling manual method is employed. The scale for the species in the bulk flow is $10^{-5}$ and the scale for the species in the surface is $10^{-12}$. In this work, the $\mathrm{CO}_{2}$ photoreduction process is considered to be steady-state, which is the same as described in other literatures [24,25], and thus, the simulation was solved by the stationary solver. In addition, modeling the deactivation is a separate issue as there are many unknown factors with respect to what the causes are such as catalyst deactivation and external conditions. For example, Thompson et al. [11] introduced a probability function to approximate the loss of active sites or deactivation.

\subsection{Mesh}

Figure 2 shows the physical model of the $\mathrm{CO}_{2}$ photoreduction reactor and mesh in this work. Figure 2(a) shows the physical model as described in Section 2.1. The mesh 1, shown in Figs. 2(b-d), has 179856 grids with corner refinement, boundary layers and film surface refinement, which was automatically generated based on the usercontrolled mesh setting in COMSOL and element sizes were calibrated for the physical principle of fluid dynamics. Mesh 2, shown in Fig. 2(e), comprises 288781 grids and was generated by using COMSOL predefined normal method for fluid dynamics. The percentages of difference between these two meshes for the final $\mathrm{CH}_{4}$ concentration, $\mathrm{CO}$ concentration and $\mathrm{H}_{2}$ concentration are $0.0 \%, 3.0 \%$ and $4.3 \%$, respectively. Therefore, mesh 1 with 179856 grids was used in this work.

\subsection{Simulation conditions}

The simulation conditions are described here. The site density is $3.6 \times 10^{-6} \mathrm{~mol} \cdot \mathrm{m}^{-2}$ or 2.31 sites $\cdot \mathrm{nm}^{-2}$ [26]. The specific surface area of $\mathrm{P} 25 \mathrm{TiO}_{2}$ is $53.31 \mathrm{~m}^{2} \cdot \mathrm{g}^{-1}$ [11]. The diffusivity on the surface is $5 \times 10^{-8} \mathrm{~m}^{2} \cdot \mathrm{s}^{-1}$ [27]. The temperature of the reactor is fixed at $314.15 \mathrm{~K}$, which is the same as the temperature of the hotplate. Finally, the average concentration of the gas outlet is regarded as the species concentration determined by the GC. The average intensity on the surface of the photocatalyst is $160 \mathrm{~W} \cdot \mathrm{m}^{-2}$ [11], which was measured by using a fiber optic guide and an OmniCure R2000 radiometer. The physical properties of the gas species and properties of gas adsorption on the $\mathrm{TiO}_{2}$ photocatalyst are shown in Table 2. The gas adsorption data were obtained from prior published work [22]. This is also the case for $\mathrm{CO}_{2}$ and $\mathrm{H}_{2} \mathrm{O}$ equilibrium constants [28] and the other equilibrium constants were estimated based on the literature [22,26-28] and matched with the experimental results under the conditions of $\mathrm{PCO} 2 \mathrm{H}$.

$A_{\mathrm{r}}$ for reaction Eqs. (20), (21) and (22) is $6.1 \times 10^{38}$, $8.2 \times 10^{17} \mathrm{~m}^{4} \cdot \mathrm{s}^{-1} \cdot \mathrm{W}^{-1} \cdot \mathrm{mol}^{-1}$ and $1.1 \times 10^{41} \mathrm{~m}^{8} \cdot \mathrm{s}^{-1} \cdot \mathrm{W}^{-1} \cdot \mathrm{mol}^{-3}$, respectively. $E_{\mathrm{a}}$ for reaction Eqs. (20), (21) and (22) is $239.0,67.54$ and $42.5 \mathrm{~kJ} \cdot \mathrm{mol}^{-1}$, respectively. The activation energy is estimated from the conversion of the

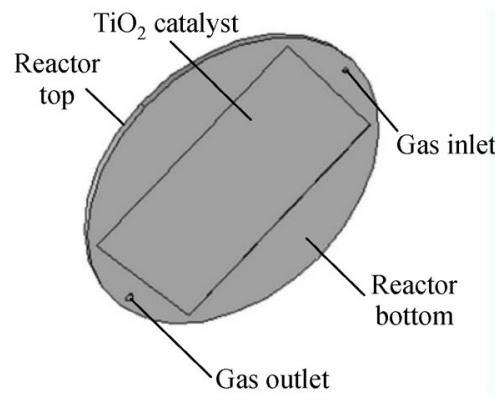

(a)

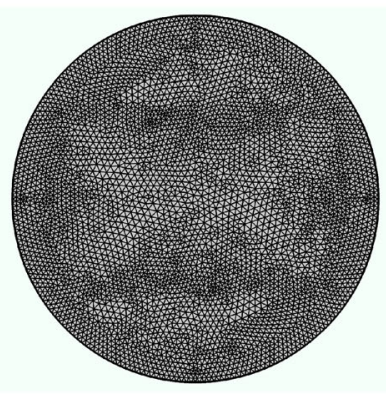

(b)

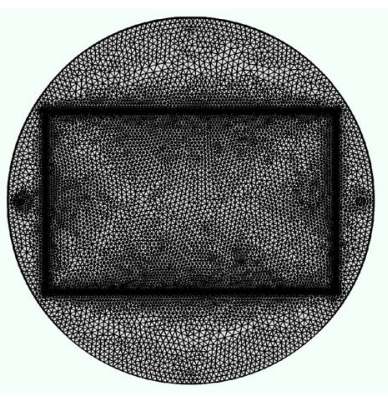

(c)

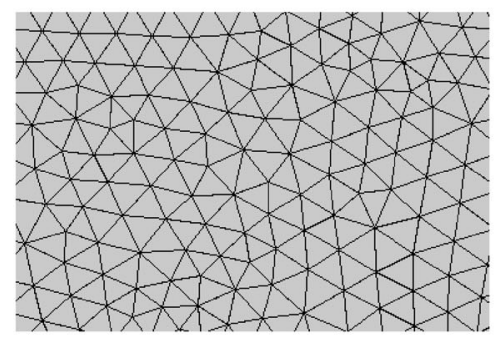

(d)

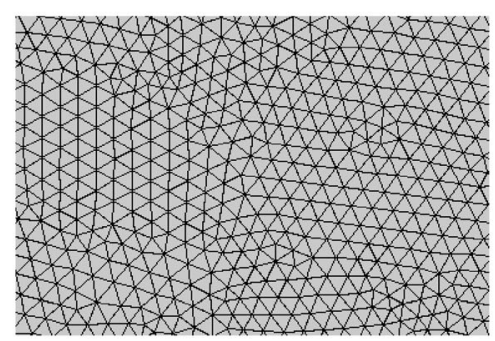

(e)

Fig. 2 Physical model and mesh: (a) physical model; (b) mesh 1 from top view; (c) mesh 1 from bottom view; (d) mesh 1 at the local area; (e) mesh 2 at the local area. 
Table 2 Physical properties of gas species and properties of gas adsorption for the $\mathrm{TiO}_{2}$ photocatalyst $[22,28-30]$

\begin{tabular}{|c|c|c|c|c|c|c|}
\hline \multirow{2}{*}{ Gas } & \multirow{2}{*}{$D_{\mathrm{f}} /\left(\mathrm{m}^{2} \cdot \mathrm{s}^{-1}\right)$} & \multicolumn{2}{|c|}{ Adsorption } & \multirow{2}{*}{$K_{\mathrm{e}} / \mathrm{Bar}^{-1}$} & \multirow{2}{*}{$\mu /(\mathrm{Pa} \cdot \mathrm{s})$} & \multirow{2}{*}{$\rho /\left(\mathrm{kg} \cdot \mathrm{m}^{-3}\right)$} \\
\hline & & $A_{\mathrm{d}} / \mathrm{s}^{-1}$ & $-\Delta H_{\mathrm{ad}} /\left(\mathrm{kJ} \cdot \mathrm{mol}^{-1}\right)$ & & & \\
\hline$\overline{\mathrm{Ar}}$ & $1.89 \times 10^{-5}$ & $10^{12.8}$ & 8.4 & 0.021 & $2.23 \times 10^{-5}$ & 1.78 \\
\hline $\mathrm{CO}_{2}$ & $1.60 \times 10^{-5}$ & $10^{19.6}$ & 77.2 & 0.019 & $1.47 \times 10^{-5}$ & 1.98 \\
\hline $\mathrm{H}_{2} \mathrm{O}$ & $7.56 \times 10^{-5}$ & $10^{14.6}$ & 83.7 & 8.070 & $2.55 \times 10^{-4}$ & 0.033 \\
\hline $\mathrm{H}_{2}$ & $7.56 \times 10^{-5}$ & $10^{19.6}$ & 100.0 & 0.090 & & \\
\hline $\mathrm{O}_{2}$ & $1.76 \times 10^{-5}$ & $10^{13.8}$ & 16.4 & 0.020 & & \\
\hline $\mathrm{CO}$ & $2.08 \times 10^{-5}$ & $10^{14.3}$ & 39.6 & 0.003 & & \\
\hline $\mathrm{CH}_{4}$ & $2.10 \times 10^{-5}$ & $10^{13.1}$ & 12.0 & 0.031 & & \\
\hline
\end{tabular}

potential energy level [21]. Because the frequency factors for the reaction rate constants are not known in advance, here they are assumed to the frequency factors which were obtained through simulation matching the experimental results under the condition of $\mathrm{PCO} 2 \mathrm{H}$.

\section{Results and discussions}

\subsection{UV light distribution}

The simulation of UV light distribution was performed with a two-dimensional RTE. The physical model and simulation results are shown in Fig. 3. Figure 3(a) shows the schematic diagram of physical model. The incident UV light with the intensity of $160 \mathrm{~W} \cdot \mathrm{m}^{-2}$ is irradiated on the top surface of the $\mathrm{TiO}_{2}$ thin film. The thickness of the thin film is $0.2 \mathrm{~mm}$. The simulation result is shown in Fig. 3(b). It is found that the light intensity on the top surface is ten times that of the incident light intensity due to light scattering on the surface. Moreover, the light intensity decreases steeply and approaches zero after $0.198 \mathrm{~mm}$ along the $z$-direction of the thin film. The effective thickness for UV lighting on thin film is $0.002 \mathrm{~mm}$. Finally, the UV light intensity distribution can be written in the form of Beer-Lambert equation in Eq. (25).

$$
I_{(z)}=10.2957 I_{\text {in }} \mathrm{e}^{-2971440 z}
$$

\subsection{Velocity, pressure and concentration}

In the simulation, we considered the path of $\mathrm{CO}_{2} \rightarrow$ $\mathrm{CO} \rightarrow \mathrm{CH}_{4}$ as the dominant reaction route. Therefore, seven species, including $\mathrm{Ar}, \mathrm{CO}, \mathrm{CO}_{2}, \mathrm{H}_{2}, \mathrm{O}_{2}, \mathrm{CH}_{4}$ and $\mathrm{H}_{2} \mathrm{O}$, and three reactions, including reaction Eqs. (20), (21) and (22) (Section 2.6), are considered.

Figure 4 shows the typical gas flow and $\mathrm{CO}_{2}$ photoreduction process. The modeled gas velocity distribution in the reactor and gas pressure contour are shown in Figs. 4(a) and 4(b). The gas velocity is $1-10 \times 10^{-4}$ $\mathrm{m} \cdot \mathrm{s}^{-1}$ and the gas pressure is $0.007 \mathrm{~Pa}$. The velocity distribution and pressure distribution are as expected. During the process, the $\mathrm{CO}_{2}$ and $\mathrm{H}_{2} \mathrm{O}$ concentrations in the gas flow are 9.85 and $1.02 \mathrm{~mol} \cdot \mathrm{m}^{-3}$, respectively. The $\mathrm{CO}_{2}$ and $\mathrm{H}_{2} \mathrm{O}$ concentrations on the film are $6.3 \times$ $10^{-7}$ and $2.77 \times 10^{-5} \mathrm{~mol} \cdot \mathrm{m}^{-2}$, respectively. The typical product concentrations of $\mathrm{CH}_{4}$ in the bulk flow and photocatalyst surface are up to $2.5 \times 10^{-4} \mathrm{~mol} \cdot \mathrm{m}^{-3}$ and $2.5 \times 10^{-11} \mathrm{~mol} \cdot \mathrm{m}^{-2}$, respectively, as shown in Figs. 4(c) and $4(\mathrm{~d})$. The concentrations of $\mathrm{CH}_{4}$ in the gas bulk and on the surface rise along the direction from gas inlet to gas outlet.
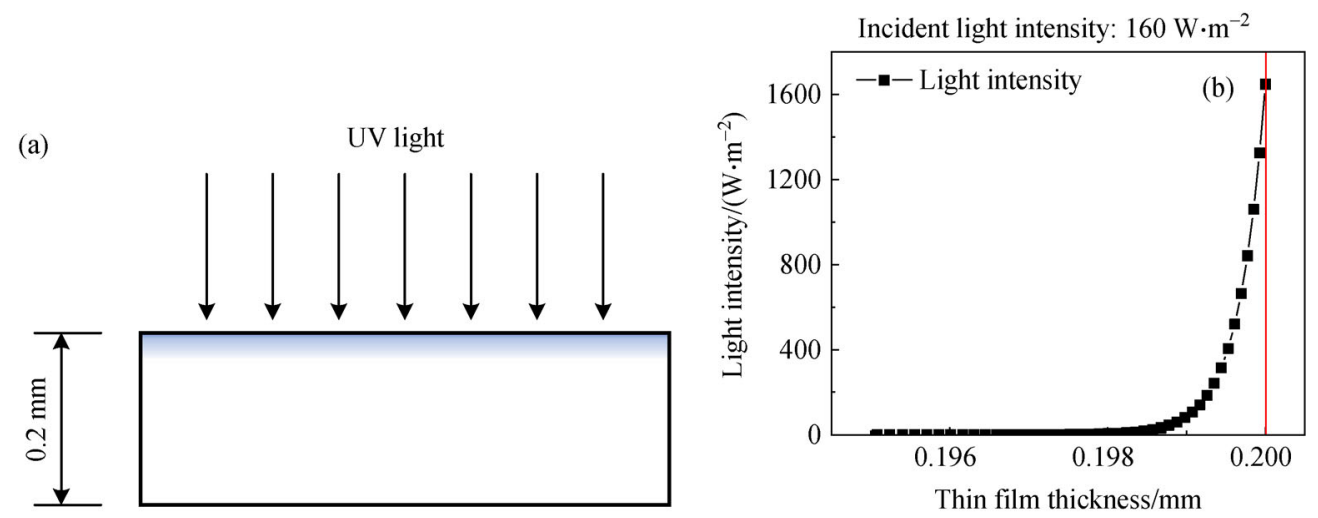

Fig. 3 UV light irradiation along the $z$-direction of the thin film: (a) physical model and (b) light intensity along the $z$-direction of the thin film. 

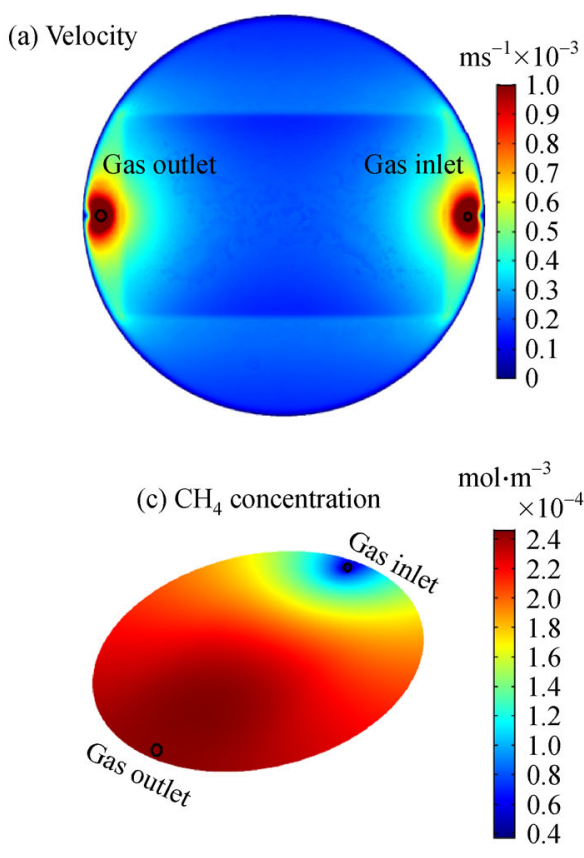

(b) Pressure
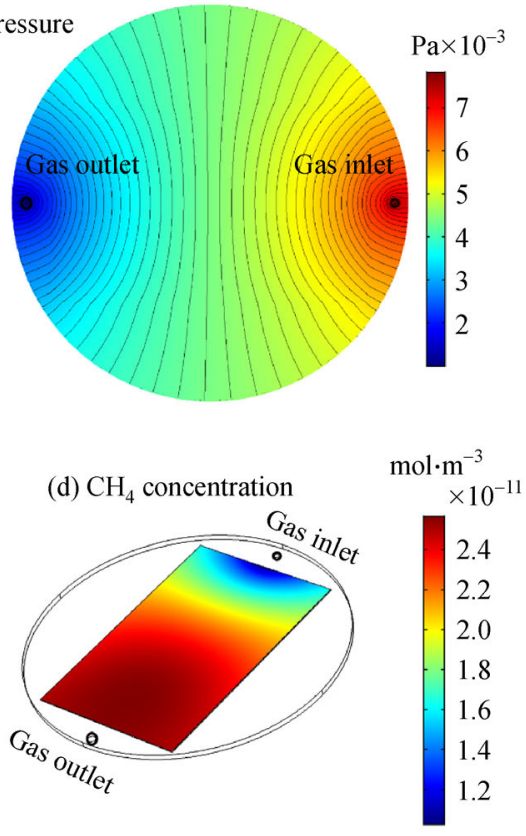

Fig. 4 Velocity, pressure and generated $\mathrm{CH}_{4}$ distribution in the reactor. (a) Velocity from top view and (b) pressure contour; (c) $\mathrm{CH}_{4}$ concentration in the bulk flow, which released from $\mathrm{CH}_{4}$ on the catalyst surface; (d) $\mathrm{CH}_{4}$ concentration on the photocatalyst surface, which generated from the photoreaction.

\subsection{Validation of the models}

The comparison between simulation and experimental results for $\mathrm{CH}_{4}, \mathrm{H}_{2}$ and $\mathrm{CO}$ concentrations is shown in Fig. 5. It can be seen that increasing $\mathrm{CO}_{2}$ partial pressure from 25.72 to $98.38 \mathrm{kPa}$ leads to the decrease of $\mathrm{CH}_{4}$ concentration from $2.44 \times 10^{-4}$ to $1.51 \times 10^{-4} \mathrm{~mol} \cdot \mathrm{m}^{-3}$, as shown in Fig. 5(a). These match the experimental results for $\mathrm{CH}_{4}$ concentration decreasing from $2.45 \times 10^{-4}$ to $0.87 \times 10^{-4} \mathrm{~mol} \cdot \mathrm{m}^{-3}$. The discrepancy of the simulation, which is the difference between simulation value and experimental value, $\delta_{\text {sim }}$, is calculated using Eq. (26), which averages deviations between simulation and experimental values:

$$
\delta_{\text {sim }}=\frac{\sum_{i=1}^{i=N} \frac{\left|d_{\text {sim }}-d_{\exp }\right|}{d_{\exp }}}{N},
$$

where $d_{\text {sim }}$ is the simulation value; $d_{\exp }$ is the experimental value; $N$ is the number of data pairs.

The discrepancy of $\mathrm{CH}_{4}$ yield between simulation and experiment is around $30 \%$. The predicted $\mathrm{CH}_{4}$ concentration by simulation is in the reasonable range of the experimental data. Dilla et al. [24] also reported that increasing $\mathrm{CO}_{2}$ concentration decreases the $\mathrm{CH}_{4}$ yield due to the competition between $\mathrm{O}_{2}$ and $\mathrm{CO}_{2}$. Delavari et al. [31] reported that with increasing $\mathrm{CO}_{2}$ partial pressure, there is an initial increase of $\mathrm{CH}_{4}$ yield, followed by a decrease. Thompson et al. [9] pointed out that there are two reasons for the decrease of $\mathrm{CH}_{4}$ yield: 1) $\mathrm{CO}_{2}$ dominates adsorption over $\mathrm{H}_{2} \mathrm{O}$ to active sites; 2) an increase in repulsion between adsorbed $\mathrm{CO}_{2}$ leading to larger surface diffusion activation energies causing reduced surface mobility. However, higher adsorption equilibrium constant for $\mathrm{H}_{2} \mathrm{O}$ over $\mathrm{CO}_{2}$ has also been reported [28]. The simulation work here has found that the $\mathrm{CH}_{4}$ concentration has a linear proportional relationship with $[\mathrm{CO}]$ or of $\left[\mathrm{H}_{2}\right]^{3}$ (where 3 stands for the third order reaction for $\left[\mathrm{H}_{2}\right]$ ). The decrease of $\mathrm{CH}_{4}$ concentration is due to the decrease of the $\mathrm{H}_{2}$ concentration in the experimental conditions, e.g., $\mathrm{PCO} 2 \mathrm{H}, \mathrm{PCO} 2 \mathrm{I}$ and $\mathrm{PCO} 2 \mathrm{~L}$. At the same time, the simulation studies also show that increasing $\mathrm{CO}_{2}$ partial pressure from 25.72 to $98.38 \mathrm{kPa}$ results in lower $\mathrm{H}_{2}$ yields from $0.50 \times 10^{-4}$ to $0.25 \times 10^{-4} \mathrm{~mol} \cdot \mathrm{m}^{-3}$ (Fig. 5(b)). In contrast, the experimental results show that the $\mathrm{H}_{2}$ yield decreases from $0.49 \times 10^{-4}$ to $0.18 \times 10^{-4} \mathrm{~mol} \cdot \mathrm{m}^{-3}$. The simulation discrepancy of $\mathrm{H}_{2}$ yield is about $30 \%$. The $\mathrm{CO}$ concentrations from experiments are in the range of $0.98 \times$ $10^{-4}-1.15 \times 10^{-4} \mathrm{~mol} \cdot \mathrm{m}^{-3}$. The predicted CO concentration increases from $1.08 \times 10^{-4}$ to $5.32 \times 10^{-4} \mathrm{~mol} \cdot \mathrm{m}^{-3}$ (Fig. 5(c)). The simulated data predicted that $\mathrm{CO}$ concentration increases with higher $\mathrm{CO}_{2}$ partial pressure under certain conditions, e.g., $98.38 \mathrm{kPa}$. This is different from the experimental data trend reporting that $\mathrm{CO}$ concentration decreases with increasing $\mathrm{CO}_{2}$ partial pressure. However, the rule for predicted $\mathrm{CO}$ concentration matches the experiments by Lo et al. [32]. It demonstrates 
that under some certain conditions, our model can still fully appropriately predict the trend with increasing $\mathrm{CO}_{2}$ pressure.

The experimental studies (Fig. 5(d)) show that with increasing $\mathrm{H}_{2} \mathrm{O}$ partial pressure, the $\mathrm{CH}_{4}$ concentration is in the range of $1.92 \times 10^{-4}-2.82 \times 10^{-4} \mathrm{~mol} \cdot \mathrm{m}^{-3}$, while the simulation values show increasing $\mathrm{CH}_{4}$ formation from $3.05 \times 10^{-4}$ to $12.45 \times 10^{-4} \mathrm{~mol} \cdot \mathrm{m}^{-3}$. There is a big deviation between simulation and experiment for $\mathrm{CH}_{4}$ yield at the higher $\mathrm{H}_{2} \mathrm{O}$ partial pressure of $6.64 \mathrm{kPa}$ that is discussed in the following section. In addition, the simulation data show that with increasing $\mathrm{H}_{2} \mathrm{O}$ partial pressure from 2.66 to $6.64 \mathrm{kPa}$, the $\mathrm{H}_{2}$ yield goes up from $0.48 \times 10^{-4}$ to $2.53 \times 10^{-4} \mathrm{~mol} \cdot \mathrm{m}^{-3}$, as presented in
Fig. 5(e). The experimental results revealed that the production of $\mathrm{H}_{2}$ rises from $0.49 \times 10^{-4}$ to $1.27 \times 10^{-4}$ $\mathrm{mol} \cdot \mathrm{m}^{-3}$. The discrepancy of $\mathrm{H}_{2}$ yield between simulation and experiment is about 30\%. From adsorption and reaction kinetics standpoint, with increasing $\mathrm{H}_{2} \mathrm{O}$ partial pressure, the $\mathrm{H}_{2}$ and $\mathrm{CH}_{4}$ are expected to increase, as demonstrated in the experiments by Khalilzadeh and Shariati [33]. The CO concentrations in the experiments are in the range of $1.08 \times 10^{-4}-1.30 \times 10^{-4} \mathrm{~mol} \cdot \mathrm{m}^{-3}$ and the predicted $\mathrm{CO}$ concentrations are in the range of $0.07 \times$ $10^{-4}-1.03 \times 10^{-4} \mathrm{~mol} \cdot \mathrm{m}^{-3}$ (Fig. 5(f)).

With the exception of the yield of $\mathrm{CO}$ in $\mathrm{PCO} 2 \mathrm{~L}$ and the yield of $\mathrm{CH}_{4}$ in $\mathrm{PH} 2 \mathrm{OH}$, the total discrepancy of the simulation results compared to the experimental values is
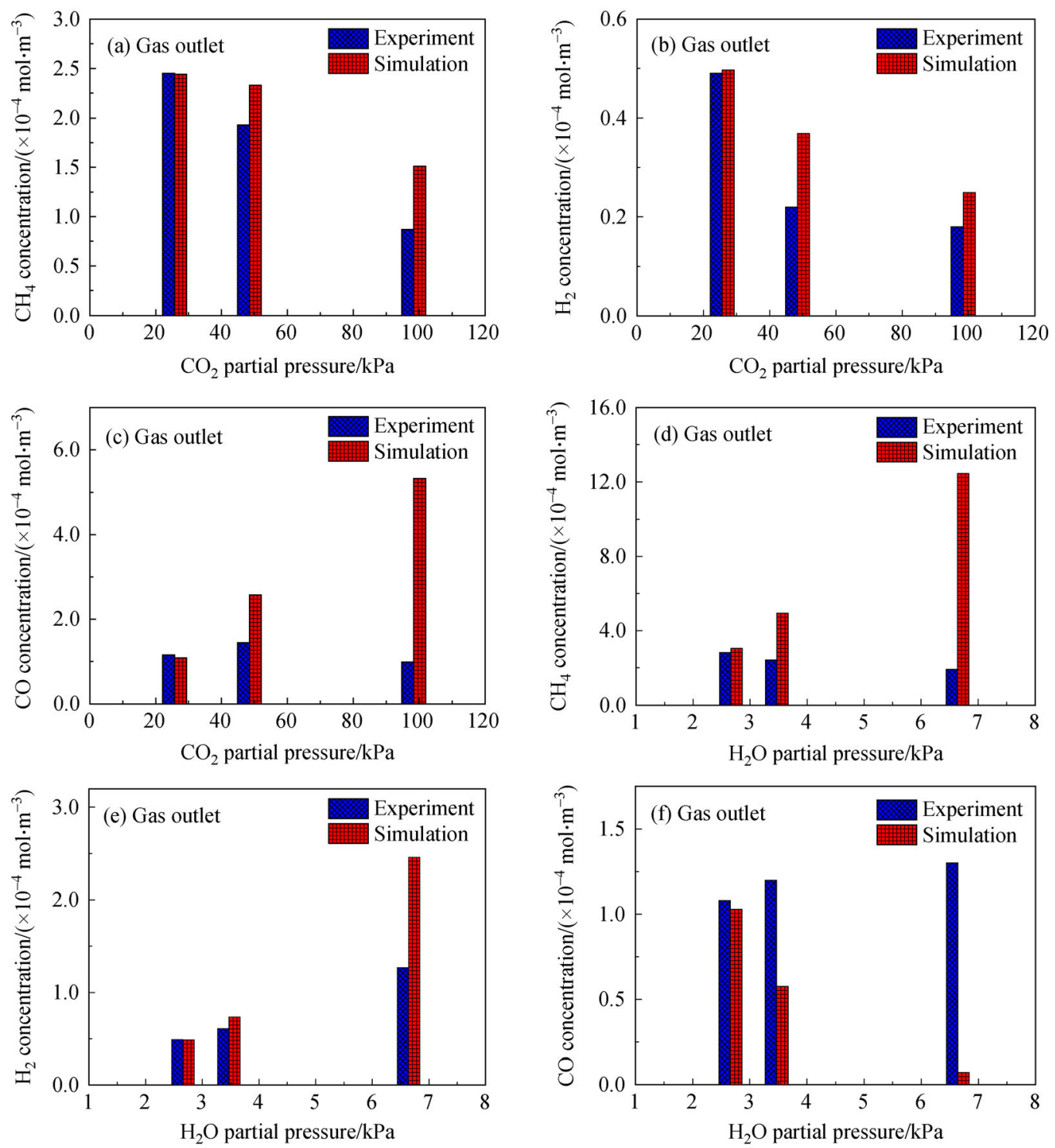

Fig. 5 Comparison between results from experiments and those based on simulation, concentration at the gas outlet under conditions of PCO2H, PCO2I and PCO2L: (a) $\mathrm{CH}_{4}$, (b) $\mathrm{H}_{2}$ and (c) CO; concentration at the gas outlet under conditions of PH2OH, PH2OI and PH2OL: (d) $\mathrm{CH}_{4}$, (e) $\mathrm{H}_{2}$ and (f) $\mathrm{CO}$. 
within 30\%-40\%, that are 10\%-20\% higher than previous published simulation work [34]. These discrepancies might be due to the reasons as follows:

1) During $\mathrm{CO}_{2}$ photoreduction, $\mathrm{CH}_{4}$ is a key final product, but $\mathrm{CO}_{2}$ also could be converted into other shortchain hydrocarbons, such as $\mathrm{HCHO}, \mathrm{HCOOH}, \mathrm{CH}_{3} \mathrm{OH}$, or even larger hydrocarbons, such as acetic acid $\left(\mathrm{CH}_{3} \mathrm{COOH}\right)$ and acetaldehyde $\left(\mathrm{CH}_{3} \mathrm{CHO}\right)$ [35]. Therefore, the activity and selectivity of reactions are key for production quantity of intermediate product $\mathrm{CO}$ and final product $\mathrm{CH}_{4}$. The activity and selectivity of these reactions are determined by the thermodynamics and kinetics of these series of reactions [36]. From Figs. 5(c) and 5(f), it can be seen that when the $\mathrm{CO}_{2}$ or $\mathrm{H}_{2} \mathrm{O}$ partial pressure are higher than 48.44 or $3.47 \mathrm{kPa}$, respectively, the simulation result seems to contradict the experimental values. This may indicate that higher $\mathrm{CO}_{2}$ and $\mathrm{H}_{2} \mathrm{O}$ partial pressures can change the selectivity of $\mathrm{CO}_{2}$ conversion to $\mathrm{CH}_{4}$ and $\mathrm{CO}$ might be used to produce other products than $\mathrm{CH}_{4}$. Kočí et al. [20] also demonstrated the $\mathrm{CO}_{2}$ pressure influenced the $\mathrm{CO}_{2}$ conversion to $\mathrm{CH}_{4}$ in a gas-liquid-solid three-phase photoreactor. Unfortunately, Thompson's paper [11] did not report other potential products and only focused on $\mathrm{CO}$ and $\mathrm{CH}_{4}$ as the main products. This may indicate that the combination of experiments and simulation could provide further understanding of the reaction mechanism of $\mathrm{CO}_{2}$ photoreduction and also help to avoid the omission of reporting key experimental data. It also may be concluded that the current simulation and simplified reaction kinetics are only suitable for $\mathrm{CO}_{2}$ and $\mathrm{H}_{2} \mathrm{O}$ partial pressures below 48.44 and $3.47 \mathrm{kPa}$, respectively. Moreover, higher $\mathrm{CO}_{2}$ and $\mathrm{H}_{2} \mathrm{O}$ partial pressure decrease the selectivity of $\mathrm{CO}$ conversion to $\mathrm{CH}_{4}$, and thus, may enhance the selectivity of $\mathrm{CO}_{2}$ conversion to other products, such as $\mathrm{CH}_{3} \mathrm{COOH}$. Ola and Maroto-Valer [37] demonstrated that under certain conditions, the preferential product of $\mathrm{CO}_{2}$ photoreduction is $\mathrm{CH}_{3} \mathrm{COOH}$ or $\mathrm{CH}_{3} \mathrm{CHO}$, instead of $\mathrm{CH}_{4}$. The effect of the reaction conditions on the selectivity of $\mathrm{CO}_{2}$ photoreduction will be further investigated in our future work.

2) From the simulation, it can be seen that the discrepancy of $\mathrm{CO}$ or $\mathrm{CH}_{4}$ between simulation results and experimental data are larger than that of $\mathrm{H}_{2}$. During the $\mathrm{CO}_{2}$ photoreduction process, $\mathrm{O}_{2}$ is generated. $\mathrm{H}_{2}$ can be oxidized by $\mathrm{O}_{2} / \mathrm{O}_{2}{ }^{-}$more easily than $\mathrm{CO}$ and $\mathrm{CH}_{4}$. Thus, it seems that $\mathrm{O}_{2} / \mathrm{O}_{2}{ }^{-}$influences $\mathrm{H}_{2}$ more than $\mathrm{CO}$ and $\mathrm{CH}_{4}$. However, because $\mathrm{CO}$ and $\mathrm{CH}_{4}$ are generated by reduction of $\mathrm{CO}_{2}$ and $\mathrm{CO}$ through generated $\mathrm{H}_{2}$ (Eqs. (21) and (22)), $\mathrm{O}_{2} / \mathrm{O}_{2}^{-}$can greatly influence production of $\mathrm{CO}$ and $\mathrm{CH}_{4}$ through free $\mathrm{H}_{2}$ as well. For the $\mathrm{CO}$ generation reaction (Eq. (21)), the reaction rate is $k_{\mathrm{r}}[\mathrm{CO}] \times\left[\mathrm{CO}_{2}\right] \times\left[\mathrm{H}_{2}\right]$. For the $\mathrm{CH}_{4}$ generation reaction (Eq. (22)), the reaction rate is $k_{\mathrm{r} \_}\left[\mathrm{CH}_{4}\right] \times[\mathrm{CO}] \times\left[\mathrm{H}_{2}\right]^{3}$. In addition, the reaction rate constant of $\mathrm{CH}_{4}$ is much higher than that of $\mathrm{CO}$ and moreover, the reaction rate constant of $\mathrm{CO}$ is much higher than that of $\mathrm{H}_{2}\left(k_{\mathrm{r}_{-}}\left[\mathrm{CH}_{4}\right]\left(9.43 \times 10^{33}\right)\right.$ for Eq. $(22) \gg k_{\mathrm{r}_{-}}$ $[\mathrm{CO}]\left(4.82 \times 10^{6}\right)$ for Eq. $(21) \gg k_{\mathrm{r} \_}\left[\mathrm{H}_{2}\right](0.11)$ for Eq. $(20)$ when $T=314.15 \mathrm{~K}$ ). Therefore, this may affect the sensitivity of our predictions, resulting in higher $\mathrm{CH}_{4}$ error than that of $\mathrm{CO}$ and much higher than that of $\mathrm{H}_{2}$. From $\mathrm{H}_{2}$ to $\mathrm{CH}_{4}$, the error would gradually spread and expand. Therefore, the reaction is very sensitive to the frequency factor of the surface reactions, $A_{\mathrm{r}}$. The 5\% change of $A_{\mathrm{r}}$ may bring $50 \%$ change of $\mathrm{CO}, \mathrm{H}_{2}$ and $\mathrm{CH}_{4}$ concentrations in the gas phase. This may be the main reason for the discrepancy from Eq. (26) in this work been higher than the general simulation. $A_{\mathrm{r}}$ may also change and sensitive to the environment, such as temperature. This implies that very small change of operating conditions, such as temperature, may bring significant changes in the gas production measured.

3) The photocatalytic activity is quite sensitive to oxygen on the surface of $\mathrm{TiO}_{2}$ because $\mathrm{O}_{2}$ seeks the oxygen vacancy defects of $\mathrm{TiO}_{2}$, producing superoxide $\mathrm{O}_{2}$ species as an oxidizing agent [38]. Thus, the superoxide species may reduce $\mathrm{CO}_{2}$ photoreduction activity. Water splitting is key for the $\mathrm{CO}_{2}$ photoreduction process and the generated $\mathrm{O}_{2}$ needs to be quickly removed from the surface. To confirm the effect of the $\mathrm{O}_{2}$ concentration on the surface, further experimental studies are needed.

A complete photocatalysis simulation requires the holistic knowledge on UV light propagation, semiconductor, fluid flow, diffusion, heat and mass transfer, adsorption and surface reactions. Currently, most models on $\mathrm{CO}_{2}$ photoreductions are empirical or mechanistic models based mainly on adsorption and surface reactions $[11,13]$. Our work here advances current models by combining UV light propagation, flow dynamics, diffusion, and adsorption kinetics, as well as reaction kinetics to describe the $\mathrm{CO}_{2}$ photoreduction process. In addition, the above discussion also indicates that combination of modeling and experiment is critical to reveal the mechanism of photocatalysis, and thus, provides a basis for further improving the efficiency of $\mathrm{CO}_{2}$ photoreduction. The simulation results reported here were based on the available experimental data and well-known $\mathrm{CO}_{2}$ photoreaction routes. With the enrichment of experimental data and development and improvement of new theoretical model formulas, the discrepancies are expected to be reduced further. Therefore, it is also possible to enhance further understanding of light-driven reactions.

\subsection{Effect of $\mathrm{CO}$ and $\mathrm{H}_{2}$ adsorption equilibrium constant}

The gas adsorption equilibrium constant affects the concentration of produced gases on the surface and further influences the concentration in the bulk flow. The $\mathrm{CO}$ and $\mathrm{H}_{2}$ intermediate gases are key for the whole $\mathrm{CO}_{2}$ photoreduction process, so in this section, the effect of the $\mathrm{CO}$ and $\mathrm{H}_{2}$ adsorption equilibrium constants has been investigated under the conditions of PCO2I and PH2OI. The simulation results are shown in Fig. 6.

Figures 6(a) and 6(b) show that with increasing $\mathrm{CO}$ 
adsorption equilibrium constant from 0.0006 to 0.0106 $\mathrm{Bar}^{-1}$, the $\mathrm{CH}_{4}$ yield increases from $1.81 \times 10^{-4}$ to $2.69 \times$ $10^{-4} \mathrm{~mol} \cdot \mathrm{m}^{-3}$ and the $\mathrm{CO}$ yield decreases from $4.36 \times 10^{-4}$ to $1.32 \times 10^{-4} \mathrm{~mol} \cdot \mathrm{m}^{-3}$. Figures $6(\mathrm{~d})$ and $6(\mathrm{e})$ show that with increasing $\mathrm{H}_{2}$ adsorption equilibrium constant from 0.07 to $0.13 \mathrm{Bar}^{-1}$, the concentration of $\mathrm{CH}_{4}$ increases from $4.80 \times 10^{-4}$ to $5.10 \times 10^{-4} \mathrm{~mol} \cdot \mathrm{m}^{-3}$ and the $\mathrm{H}_{2}$ concentration decreases from $0.90 \times 10^{-4}$ to $0.53 \times 10^{-4}$ $\mathrm{mol} \cdot \mathrm{m}^{-3}$. These trends indicate that the $\mathrm{CO}$ and $\mathrm{H}_{2}$ concentrations on the surface increase. The decrease of the $\mathrm{CO}$ or $\mathrm{H}_{2}$ concentration in the bulk flow is caused by the increase of the $\mathrm{CO}$ or $\mathrm{H}_{2}$ concentration on the photocatalyst surface from $0.77 \times 10^{-12}$ to $4.15 \times 10^{-12}$ and from $2.34 \times 10^{-11}$ to $2.46 \times 10^{-11} \mathrm{~mol} \cdot \mathrm{m}^{-2}$, as shown in
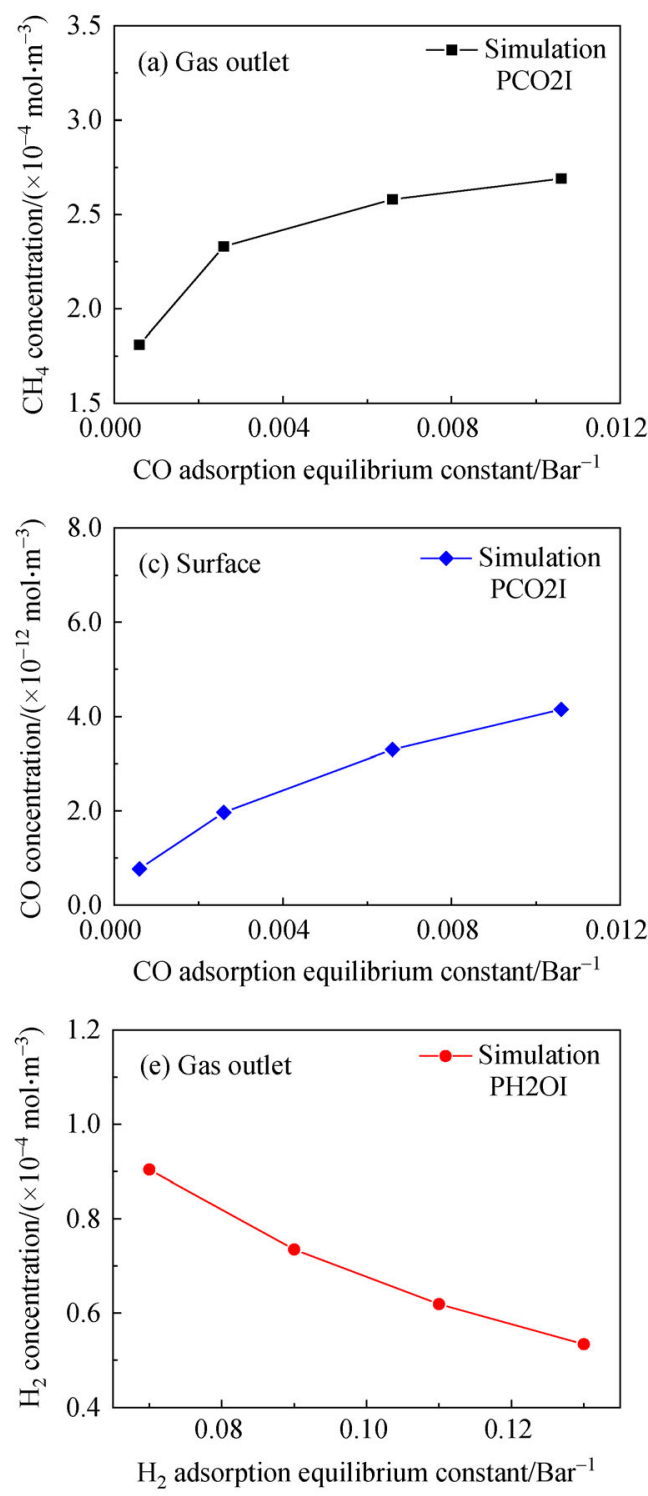

Figs. 6(c) and 6(f) because of the higher $\mathrm{CO}$ or $\mathrm{H}_{2}$ equilibrium constants.

The simulation results in Fig. 6 show that the adsorption equilibrium constant highly influences the yields of $\mathrm{CH}_{4}$, $\mathrm{CO}$ and $\mathrm{H}_{2}$. The increase of $\mathrm{CO}$ and $\mathrm{H}_{2}$ adsorption equilibrium constants enhances the adsorption quantities of $\mathrm{CO}$ and $\mathrm{H}_{2}$ on the photocatalyst surface.

\subsection{Effect of adsorption site concentration}

The number of bare sites plus the number of sites occupied by the gases is equal to the total number of adsorption sites on the photocatalyst surface. When the total number of adsorption sites is increased, it is possible for more gases to
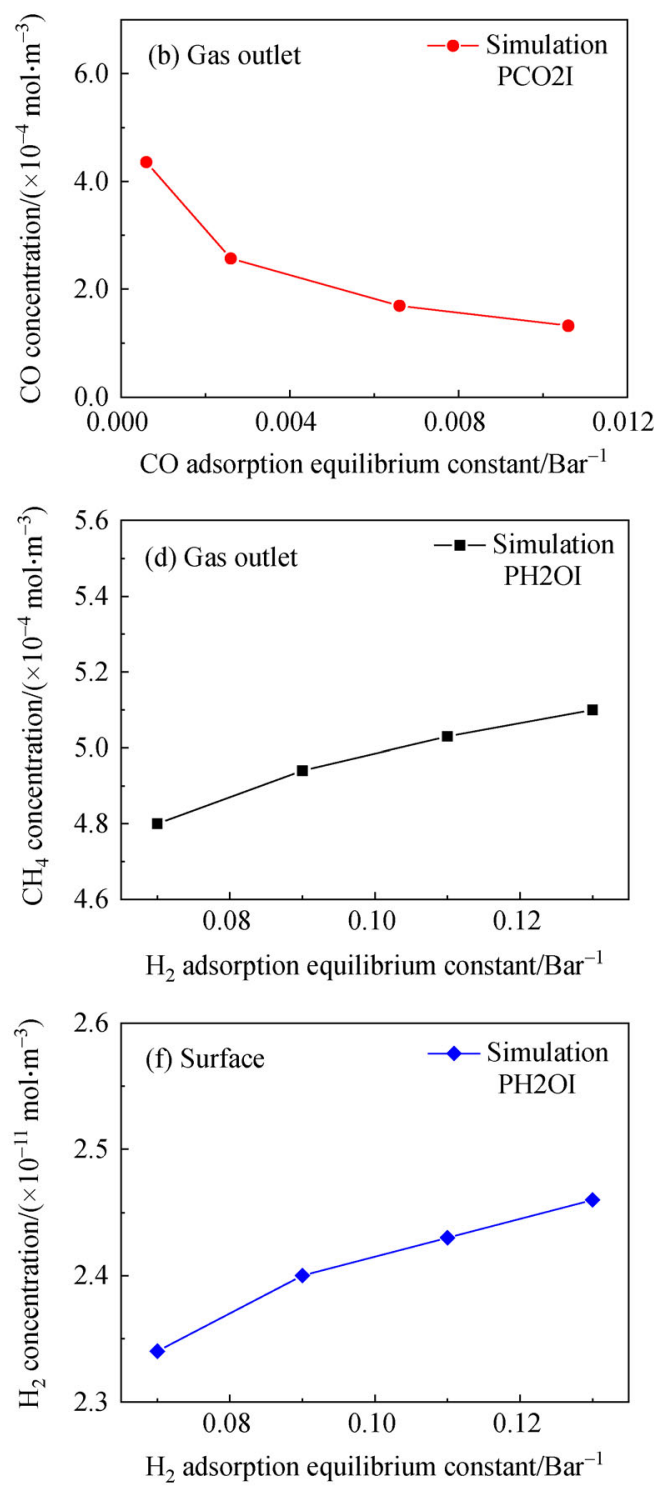

Fig. 6 Effect of $\mathrm{CO}$ and $\mathrm{H}_{2}$ adsorption equilibrium constant. (a) $\mathrm{CH}_{4}$ yield under PCO2I; (b) $\mathrm{CO}$ yield under PCO2I; (c) CO concentration on the photocatalyst surface under PCO2I; (d) $\mathrm{CH}_{4}$ yield under PH2OI; (e) $\mathrm{H}_{2}$ yield under PH2OI; (f) $\mathrm{H}_{2}$ concentration on the photocatalyst surface under PH2OI. 
be adsorbed on the photocatalyst surface. Therefore, the concentration of adsorption sites on the surface of the photocatalyst may strongly influence the concentration of produced gases on the surface as well as the concentration in the bulk flow. In this section, we explore the effect of adsorption site concentration on $\mathrm{CO}_{2}$ photoreduction under the conditions of PCO2I and PH2OI and the simulation results are shown in Fig. 7.

Figures 7(a) and 7(c) show that with increasing adsorption sites concentration from $2.6 \times 10^{-6}$ to $7.6 \times$ $10^{-6} \mathrm{~mol} \cdot \mathrm{m}^{-2}$, the $\mathrm{CH}_{4}$ yield goes up from $0.84 \times 10^{-4}$ to $24.51 \times 10^{-4} \mathrm{~mol} \cdot \mathrm{m}^{-3}$. Figures 7(b) and 7(d) show that with more adsorption sites, the concentrations of $\mathrm{H}_{2}$ and $\mathrm{CO}$ in the bulk flow decline from $0.42 \times 10^{-4}$ and $0.84 \times$ $10^{-4}$ to $0.28 \times 10^{-4}$ and $0.13 \times 10^{-4} \mathrm{~mol} \cdot \mathrm{m}^{-3}$, respectively. This indicates that more $\mathrm{CO}_{2}$ and $\mathrm{H}_{2}$ were adsorbed on the surface. Therefore, the adsorption site concentration has a great effect on the yield of $\mathrm{CH}_{4}$, where more adsorption sites result in more gas adsorbed and higher $\mathrm{CH}_{4}$ yields.

\subsection{Effects of UV light intensity}

The UV light irradiation plays a crucial role in photocatalytic processes and affects the photoreaction kinetics $[9,32]$. The reaction rate has a positive linear relationship with light intensity as shown in Eq. (23). This section examines the effect of UV light intensity on the $\mathrm{CH}_{4}$ yield. The simulation results based on $\mathrm{PCO} 2 \mathrm{H}$ are shown in Fig. 8.
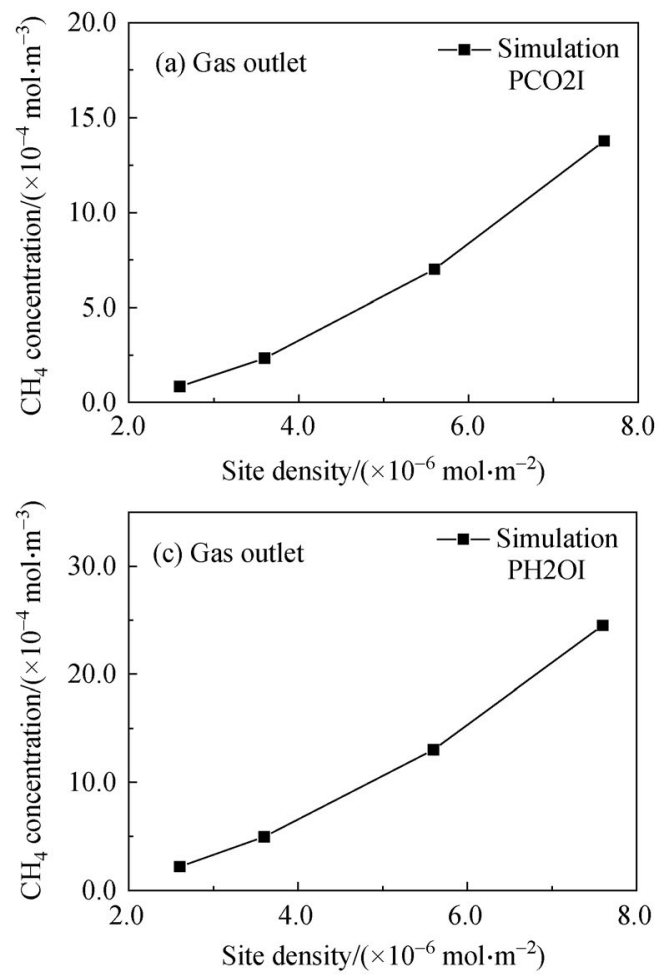

Figure 8(a) shows the yields of $\mathrm{CH}_{4}, \mathrm{CO}$ and $\mathrm{H}_{2}$ and at the gas outlet with increasing UV light intensity. Figures 8(b-d) show the adsorption concentration of $\mathrm{CH}_{4}, \mathrm{CO}$ and $\mathrm{H}_{2}$ on the surface of the photocatalyst thin film. Figures $8(\mathrm{a}), 8(\mathrm{~b})$ and $8(\mathrm{c})$ indicate that when the average UV light intensity on the surface increases from 40 to $320 \mathrm{~W} \cdot \mathrm{m}^{-2}$, the $\mathrm{CH}_{4}$ yield at the gas outlet and $\mathrm{CH}_{4}$ concentration on the surface go up from $0.27 \times 10^{-4}$ $\mathrm{mol} \cdot \mathrm{m}^{-3}$ and $0.24 \times 10^{-11} \mathrm{~mol} \cdot \mathrm{m}^{-2}$ to $5.48 \times 10^{-4} \mathrm{~mol} \cdot \mathrm{m}^{-3}$ and $4.97 \times 10^{-11} \mathrm{~mol} \cdot \mathrm{m}^{-2}$, respectively. Concurrently, the $\mathrm{CO}$ yield at the gas outlet and $\mathrm{CO}$ concentration on the surface increase from $0.56 \times 10^{-4} \mathrm{~mol} \cdot \mathrm{m}^{-3}$ and $0.43 \times$ $10^{-12} \mathrm{~mol} \cdot \mathrm{m}^{-2}$ to $1.33 \times 10^{-4} \mathrm{~mol} \cdot \mathrm{m}^{-3}$ and $1.05 \times 10^{-12}$ $\mathrm{mol} \cdot \mathrm{m}^{-2}$, respectively. However, the production of $\mathrm{H}_{2}$ is influenced by the UV light intensity limitedly. The $\mathrm{H}_{2}$ concentrations at the gas outlet and surface are in the range of $0.47 \times 10^{-4}-0.50 \times 10^{-4} \mathrm{~mol} \cdot \mathrm{m}^{-3}$ and $1.44 \times 10^{-11}$ $1.56 \times 10^{-11} \mathrm{~mol} \cdot \mathrm{m}^{-2}$, as shown in Figs. 8(a) and $8(\mathrm{~d})$. These results illuminate that the light intensity affects the production of $\mathrm{CO}$ higher than that of $\mathrm{H}_{2}$.

\subsection{Effect of temperature}

The reactor temperature obviously affects the gas adsorption and reactions, and the effect of temperature was discussed in the literature [9]. Several researchers demonstrated that the higher temperature could promote trapping reactions and activity of $\mathrm{CO}_{2}$ photoreduction [39]. In this section, the effect of different temperatures on $\mathrm{CO}_{2}$
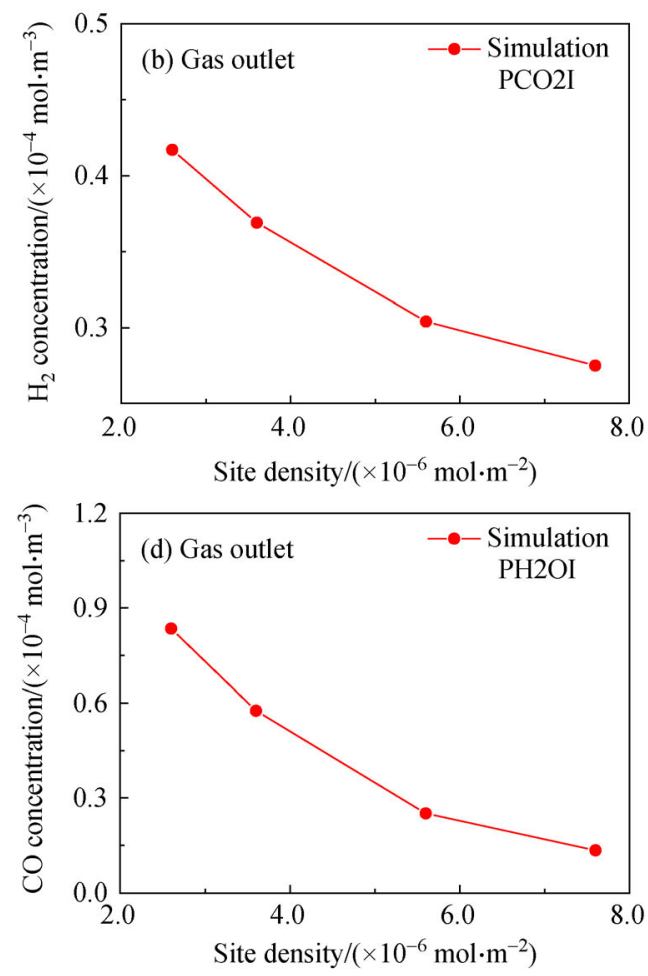

Fig. 7 Effect of adsorption site concentration. (a) $\mathrm{CH}_{4}$ yield under PCO2I; (b) $\mathrm{H}_{2}$ yield under PCO2I; (c) $\mathrm{CH}_{4}$ yield under PH2OI; (d) $\mathrm{CO}$ yield under $\mathrm{PH} 2 \mathrm{OI}$. 

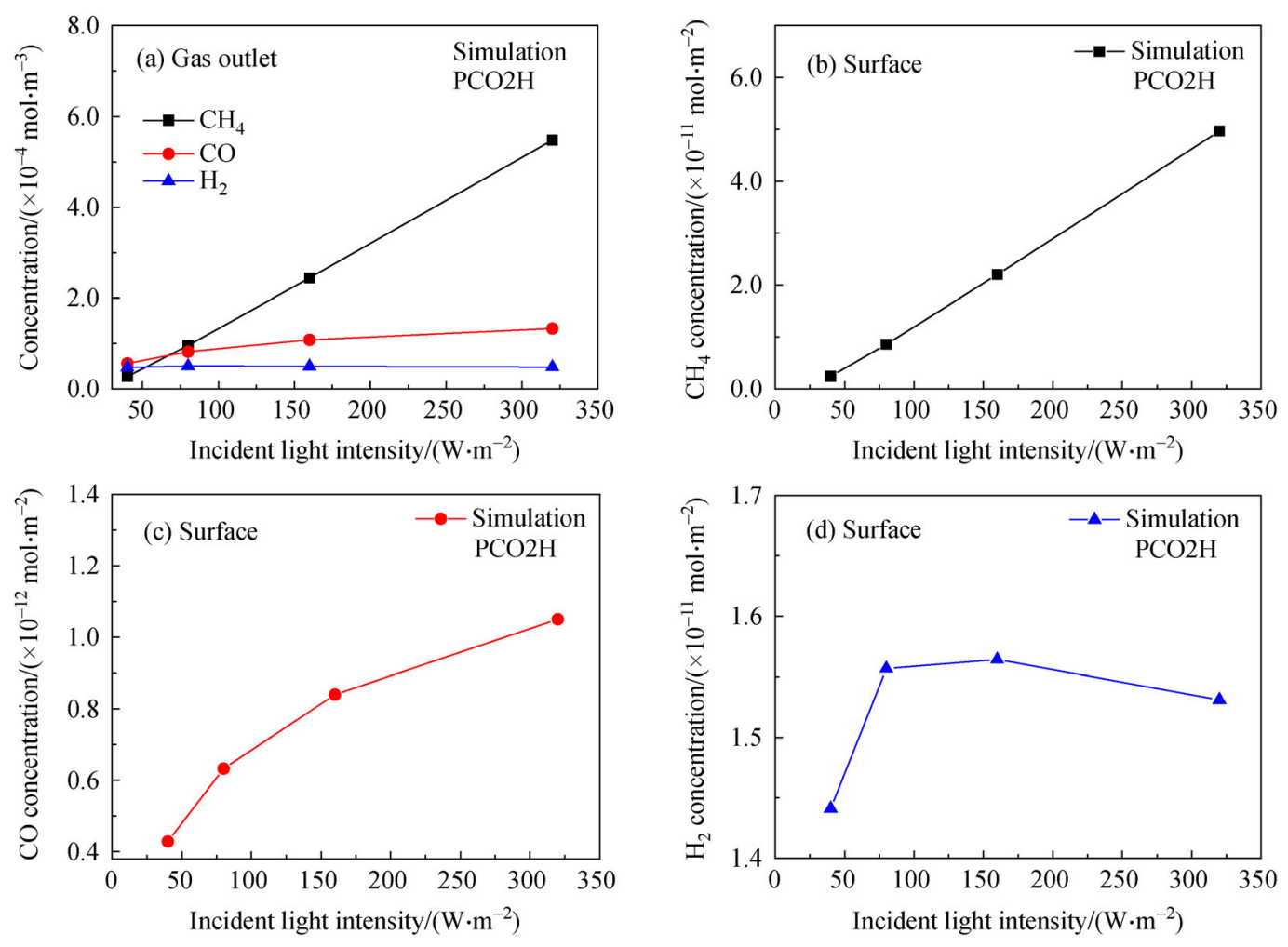

Fig. 8 Effect of increasing UV light intensity under $\mathrm{PCO} 2 \mathrm{H}$. (a) $\mathrm{CH}_{4}, \mathrm{CO}$, and $\mathrm{H}_{2}$ yields at the gas outlet; (b) $\mathrm{CH}_{4}$ concentration on the photocatalyst surface; (c) $\mathrm{CO}$ concentration on the photocatalyst surface; (d) $\mathrm{H}_{2}$ concentration on the photocatalyst surface.

photoreduction was simulated using the validated models. In the simulation, the adsorption equilibrium constant is assumed to be constant in the temperature range of $309.15 \mathrm{~K}$ to $324.15 \mathrm{~K}$. The simulation results based on $\mathrm{PCO} 2 \mathrm{H}$ are shown in Fig. 9.

Figure 9(a) shows the yields of $\mathrm{CH}_{4}, \mathrm{CO}$, and $\mathrm{H}_{2}$ at the gas outlet with increasing temperature. Figures $9(\mathrm{~b}-\mathrm{d})$ show the adsorption concentration of $\mathrm{CH}_{4}, \mathrm{CO}$ and $\mathrm{H}_{2}$ on the surface of the photocatalyst thin film with increasing temperature. As the temperature rises from $309.15 \mathrm{~K}$ to $324.15 \mathrm{~K}$, the yields of $\mathrm{CH}_{4}$ and $\mathrm{H}_{2}$ increase from $0.27 \times$ $10^{-4}$ and $0.25 \times 10^{-4}$ to $49.24 \times 10^{-4}$ and $3.25 \times 10^{-4}$ $\mathrm{mol} \cdot \mathrm{m}^{-3}$, respectively, and the concentrations of $\mathrm{CH}_{4}$ and $\mathrm{H}_{2}$ on the photocatalyst surface increase from $0.02 \times 10^{-10}$ and $0.83 \times 10^{-11}$ to $4.62 \times 10^{-10}$ and $9.84 \times 10^{-11} \mathrm{~mol} \cdot \mathrm{m}^{-2}$, respectively. The yield of $\mathrm{CO}$ is in the range of $0.04 \times$ $10^{-4}-1.08 \times 10^{-4} \mathrm{~mol} \cdot \mathrm{m}^{-3}$. The concentration of $\mathrm{CO}$ on the photocatalyst surface is in the range of $0.44 \times 10^{-13}$ $8.40 \times 10^{-13} \mathrm{~mol} \cdot \mathrm{m}^{-2}$. It seems that the yield of $\mathrm{H}_{2}$ is influenced by the temperature higher than the yield of $\mathrm{CO}$.

$\mathrm{CO}_{2}$ photoreduction process has two reaction steps, resulting in a wide range of possible potential products. Generally, the reaction steps include electron and carrier trapping reactions and radical propagation reactions. The UV light radiation with tuning wavelength may influence the selectivity of trapping reactions by energy level for driving force to overcome the reaction energy barrier. Tan et al. [40] demonstrated highly selective photoreduction of
$\mathrm{CO}_{2}$ to generate $\mathrm{CH}_{4}$ under irradiation above $600 \mathrm{~nm}$. On the other hand, selectivity toward a given final product is mainly determined by the thermodynamic and kinetic reaction parameters of the $\mathrm{CO}_{2}$ conversion reactions [36]. The issue of reaction selectivity can also be considered on the radical propagation reactions Although Kočí et al. [20] indicated that $\mathrm{CO}_{2}$ photoreduction was not sensitive significantly to small temperature change within $10 \mathrm{~K}$, Kohno et al. [41] and Anpo [35] demonstrated high temperature resulted in change of reaction selectivity. Therefore, temperature affects the reaction selectivity. As a follow-up to the work reported here, the effect of UV light intensity and temperature on selectivity of intermediation reactions and products will be investigated.

In summary, it can be seen from the simulation studies that when using stronger light intensity and higher temperature, more $\mathrm{CH}_{4}$ is produced. The tendency of gas product yields by this simulation with different UV light intensities and temperatures is in agreement with published work [32]. This conclusion gives a valuable guidance of adsorption kinetics and reaction kinetics for photoreactor and $\mathrm{CO}_{2}$ photoreduction process design.

\section{Conclusions}

In this work, the $\mathrm{CO}_{2}$ photoreduction process was simulated based on an intrinsic kinetic model by COMSOL 

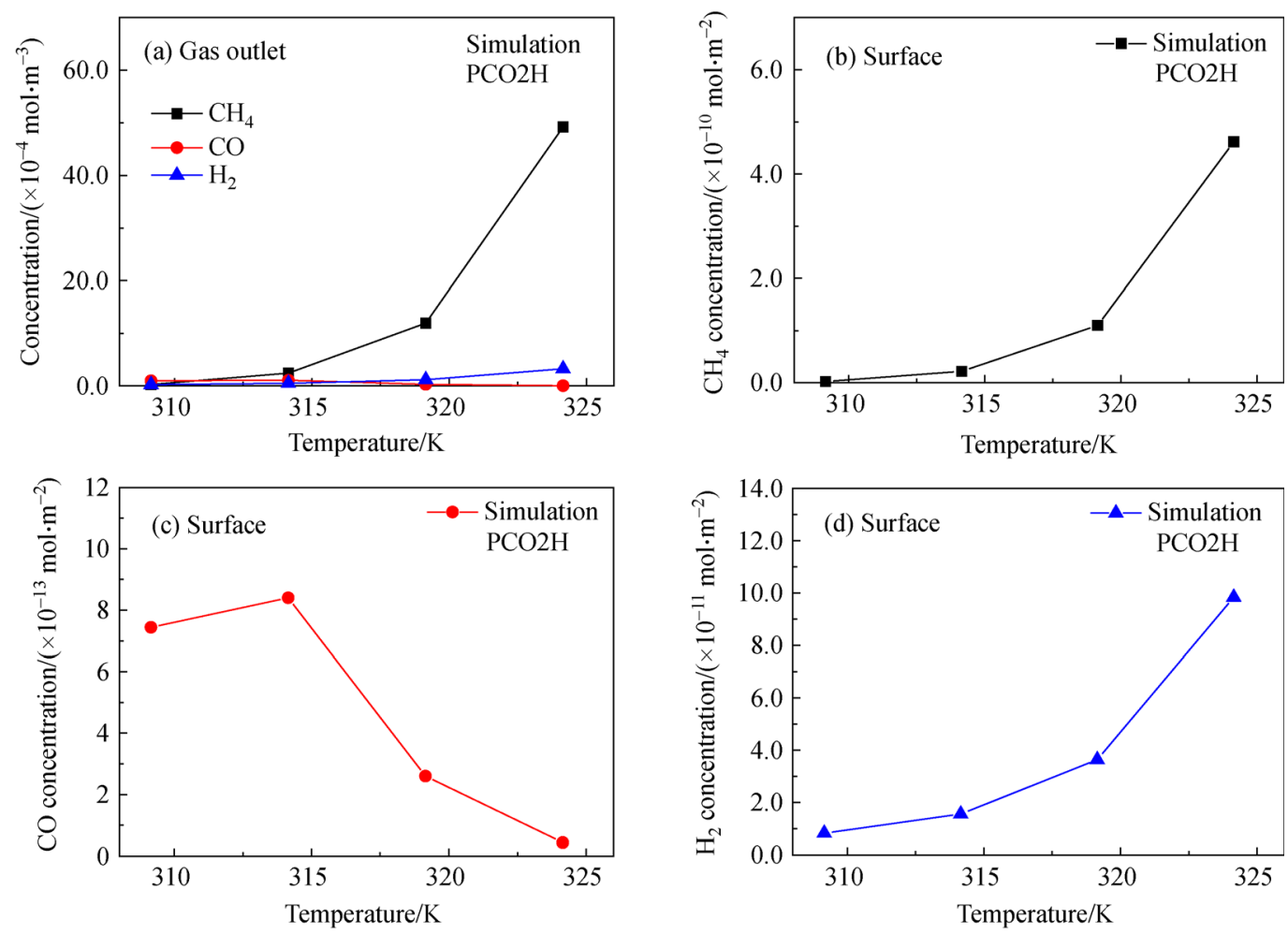

Fig. 9 Effect of increasing temperature under $\mathrm{PCO} 2 \mathrm{H}$. (a) $\mathrm{CH}_{4}, \mathrm{CO}$ and $\mathrm{H}_{2}$ yields at the gas outlet; (b) $\mathrm{CH}_{4}$ concentration on the photocatalyst surface; (c) $\mathrm{CO}$ concentration on the photocatalyst surface; (d) $\mathrm{H}_{2}$ concentration on the photocatalyst surface.

version 5.2a including three modules: laminar flow module, species dilute transportation module and general form boundary PDE module. The mechanism of $\mathrm{CO}_{2}$ photoreduction process is the reaction potential path: $\mathrm{CO}_{2}$ $\rightarrow \mathrm{CO} \rightarrow \mathrm{HCHO} \rightarrow \mathrm{CH}_{3} \mathrm{OH} \rightarrow \mathrm{CH}_{4}$. In our work, the intrinsic kinetic model comprises two parts: Langmuir adsorption/desorption and surface reactions. The novelty of this work is the combination of the intrinsic kinetic model with the CFD model to investigate the $\mathrm{CO}_{2}$ photoreduction on the $\mathrm{TiO}_{2}$ thin film. The simulation results are compared with the experimental results, and it was demonstrated that the simulation results are in the reasonable range of the experiments at the low $\mathrm{CO}_{2}$ and $\mathrm{H}_{2} \mathrm{O}$ partial pressure. The simulation shows that with increasing $\mathrm{CO}_{2}$ partial pressure, the $\mathrm{CH}_{4}$ and $\mathrm{H}_{2}$ yields decrease and $\mathrm{CO}$ yield increases; while with increasing $\mathrm{H}_{2} \mathrm{O}$ partial pressure, the $\mathrm{CH}_{4}$ and $\mathrm{H}_{2}$ yields increase and $\mathrm{CO}$ decreases. Some key factors such as adsorption, temperature and UV lighting have also been investigated in this work. The adsorption sites and equilibrium constant, temperature and UV lighting affect the surface concentration, and therefore, influences the yields of $\mathrm{CH}_{4}, \mathrm{CO}$ and $\mathrm{H}_{2}$.

From the analysis of the operating parameters above, it can be concluded that gas adsorption on the photocatalyst surface is one of the crucial steps for improving the $\mathrm{CH}_{4}$ yield in the $\mathrm{CO}_{2}$ photoreduction process. Water splitting generates $\mathrm{H}_{2}$ and most of surface reactions depend on $\mathrm{H}_{2}$ or $\mathrm{H}^{+}$on the photocatalyst surface. The separation of water splitting and $\mathrm{CO}_{2}$ photoreduction by a proton exchange membrane could improve $\mathrm{CO}_{2}$ conversion efficiency [15]. Therefore, the novel twin photoreactor [15], photoelectrocatalytic process $[42,43]$ and thin-film reactor with modified photocatalysts [44] might be promising reactor designs for $\mathrm{CO}_{2}$ photoreduction.

\section{Nomenclatures}

$A_{\mathrm{d}} \quad$ frequency factor for gas desorption $\left(\mathrm{s}^{-1}\right)$

$A_{\mathrm{e}} \quad$ effective area for UV lighting $\left(\mathrm{m}^{2}\right)$

$A_{\mathrm{r}} \quad$ frequency factor for reaction $\left(\mathrm{m}^{2} \cdot \mathrm{s}^{-1} \cdot \mathrm{mol}^{-1}\right.$ or $\left.\mathrm{m}^{6} \cdot \mathrm{s}^{-1} \cdot \mathrm{mol}^{-3}\right)$

$A_{\mathrm{t}} \quad$ total area of the photocatalyst $\left(\mathrm{m}^{2}\right)$

$c_{i} \quad$ mole concentration of $i$ species $\left(\mathrm{mol} \cdot \mathrm{m}^{-3}\right.$ (bulk) or $\mathrm{mol} \cdot \mathrm{m}^{-2}$ (surface))

$\left[c_{\mathrm{ad}}\right]$ gas concentration adsorbed on the surface $\left(\mathrm{mol} \cdot \mathrm{m}^{-2}\right)$

$C_{\mathrm{p}} \quad$ heat capacity $\left(\mathrm{J} \cdot \mathrm{kg}^{-1} \cdot \mathrm{K}^{-1}\right)$

$d_{\exp } \quad$ experimental value $\left(\mathrm{mol} \cdot \mathrm{m}^{-3}\right)$

$d_{\text {sim }} \quad$ simulation value $\left(\mathrm{mol} \cdot \mathrm{m}^{-3}\right)$

$D_{i} \quad$ gas diffusivity of the $i$ species $\left(\mathrm{m}^{2} \cdot \mathrm{s}^{-1}\right)$

$E_{\mathrm{a}} \quad$ activation energy for reaction $\left(\mathrm{kJ} \cdot \mathrm{mol}^{-1}\right)$

$E_{\mathrm{d}} \quad$ activation energy for gas desorption $\left(\mathrm{kJ} \cdot \mathrm{mol}^{-1}\right)$ 
$\Delta H_{\mathrm{ad}} \quad$ adsorption enthalpy $\left(\mathrm{kJ} \cdot \mathrm{mol}^{-1}\right)$

$\Delta H_{\mathrm{r}} \quad$ reaction heat $\left(\mathrm{kJ} \cdot \mathrm{mol}^{-1}\right)$

I light intensity $\left(\mathrm{W} \cdot \mathrm{m}^{-2}\right)$

$I(\Omega) \quad$ radiative intensity at a given position following the $\Omega$ direction $\left(\mathrm{W} \cdot \mathrm{m}^{-2}\right)$

$I_{\text {in }} \quad$ intensity of incident $\mathrm{UV}$ light $\left(\mathrm{W} \cdot \mathrm{m}^{-2}\right)$

$k \quad$ thermal conductivity $\left(\mathrm{W} \cdot \mathrm{m}^{-1} \cdot \mathrm{K}^{-1}\right)$

$k_{\mathrm{r}} \quad$ reaction constant $\left(\mathrm{m}^{2} \cdot \mathrm{s}^{-1} \cdot \mathrm{mol}^{-1}\right.$ or $\left.\mathrm{m}^{6} \cdot \mathrm{s}^{-1} \cdot \mathrm{mol}^{-3}\right)$

$k_{\text {ad }} \quad$ adsorption constant $\left(\mathrm{m} \cdot \mathrm{s} \cdot \mathrm{kg}^{-1}\right)$

$k_{\mathrm{de}} \quad$ desorption constant $\left(\mathrm{s}^{-1}\right)$

$K \quad$ adsorption equilibrium constant $\left(\mathrm{Bar}^{-1}\right)$

$r_{\mathrm{r}} \quad$ reaction rate $\left(\mathrm{mol} \mathrm{m}^{-2} \cdot \mathrm{s}^{-1}\right)$

$r_{\text {ad }} \quad$ adsorption rate $\left(\mathrm{mol} \cdot \mathrm{m}^{-2} \cdot \mathrm{s}^{-1}\right)$

$r_{\mathrm{de}} \quad$ desorption rate $\left(\mathrm{mol} \cdot \mathrm{m}^{-2} \cdot \mathrm{s}^{-1}\right)$

$p \quad$ gas partial pressure (Pa or Bar)

$m \quad$ order for the reaction $(-)$

$m_{\mathrm{s}} \quad$ mass source $\left(\mathrm{kg} \cdot \mathrm{m}^{-3} \cdot \mathrm{s}^{-1}\right)$

$n \quad$ order for the reaction $(-)$

$N \quad$ number of data $(-)$

$r \quad$ radius $(\mathrm{m})$

$\mathrm{R} \quad$ gas constant, $8.314\left(\mathrm{~J}^{-1} \cdot \mathrm{K}^{-1} \cdot \mathrm{mol}^{-1}\right)$

$[S] \quad$ bare site concentration on the surface $\left(\mathrm{mol} \cdot \mathrm{m}^{-1}\right)$

$t \quad$ time (s)

$T \quad$ temperature $(\mathrm{K})$

$u \quad$ velocity $\left(\mathrm{m} \cdot \mathrm{s}^{-1}\right)$

$z \quad$ depth (m)

\section{Greek symbols}

$\beta \quad$ extinction coefficient $\left(\mathrm{m}^{-1}\right)$

$\delta_{\text {sim }} \quad$ simulation discrepancy (-)

$\kappa \quad$ absorption coefficient $\left(\mathrm{m}^{-1}\right)$

$\mu \quad$ dynamic viscosity $(\mathrm{Pa} \cdot \mathrm{s})$

$\mu_{\mathrm{L}} \quad$ attenuation of the UV light $\left(\mathrm{m}^{-1}\right)$

$\rho \quad$ density $\left(\mathrm{kg} \cdot \mathrm{m}^{-3}\right)$

$\sigma_{\mathrm{s}} \quad$ scattering coefficient $\left(\mathrm{m}^{-1}\right)$

$\omega_{0} \quad$ radius of light beam $(\mathrm{m})$

\section{Subscripts}

\section{$i, j$ gas species.}

Acknowledgements The authors thank the financial support provided by the Engineering and Physical Sciences Research Council (Grant No. EP/ K021796/1), the Research Centre for Carbon Solutions and the James Watt Scholarship Programme at Heriot-Watt University. We are also grateful for the support provided by the Buchan Chair in Sustainable Energy Engineering.

Open Access This article is licensed under a Creative Commons Attribution 4.0 International License, which permits use, sharing, adaptation, distribution and reproduction in any medium or format, as long as you give appropriate credit to the original author(s) and the source, provide a link to the Creative Commons licence, and indicate if changes were made. The images or other third party material in this article are included in the article's Creative Commons licence, unless indicated otherwise in a credit line to the material. If material is not included in the article's Creative Commons licence and your intended use is not permitted by statutory regulation or exceeds the permitted use, you will need to obtain permission directly from the copyright holder. To view a copy of this licence, visit http://creativecommons.org/licenses/by/4.0/.

\section{References}

1. Lu X, Xie P, Ingham D B, Ma L, Pourkashanian M. Modelling of $\mathrm{CO}_{2}$ absorption in a rotating packed bed using an Eulerian porous media approach. Chemical Engineering Science, 2019, 199: 302318

2. Izumi Y. Recent advances in the photocatalytic conversion of carbon dioxide to fuels with water and/or hydrogen using solar energy and beyond. Coordination Chemistry Reviews, 2013, 257(1): 171-186

3. Tan L, Peter K, Ren J, Du B, Hao X, Zhao Y, Song Y. Photocatalytic syngas synthesis from $\mathrm{CO}_{2}$ and $\mathrm{H}_{2} \mathrm{O}$ using ultrafine $\mathrm{CeO}_{2}$-decorated layered double hydroxide nanosheets under visible-light up to 600 nm. Frontiers of Chemical Science and Engineering, 2021, 15(1): 99-108

4. Song $\mathrm{G}, \mathrm{Wu} \mathrm{X}$, Xin F, Yin $\mathrm{X}$. $\mathrm{ZnFe}_{2} \mathrm{O}_{4}$ deposited on $\mathrm{BiOCl}$ with exposed (001) and (010) facets for photocatalytic reduction of $\mathrm{CO}_{2}$ in cyclohexanol. Frontiers of Chemical Science and Engineering, 2017, 11(2): 197-204

5. Hafez A M, Zedan A F, AlQaradawi S Y, Salem N M, Allam N K. Computational study on oxynitride perovskites for $\mathrm{CO}_{2}$ photoreduction. Energy Conversion and Management, 2016, 122: 207214

6. Schneider J, Matsuoka M, Takeuchi M, Zhang J, Horiuchi Y, Anpo M, Bahnemann D W. Understanding $\mathrm{TiO}_{2}$ photocatalysis: mechanisms and materials. Chemical Reviews, 2014, 114(19): 9919-9986

7. Qian R, Zong H, Schneider J, Zhou G, Zhao T, Li Y, Yang J, Bahnemann D W, Pan J H. Charge carrier trapping, recombination and transfer during $\mathrm{TiO}_{2}$ photocatalysis: an overview. Catalysis Today, 2019, 335: 78-90

8. Vorontsov A V, Valdes H, Smirniotis P G, Paz Y. Recent advancements in the understanding of the surface chemistry in $\mathrm{TiO}_{2}$ photocatalysis. Surfaces, 2020, 3(1): 72-92

9. Thompson W A, Fernandez E S, Maroto-Valer M M. Review and analysis of $\mathrm{CO}_{2}$ photoreduction kinetics. ACS Sustainable Chemistry \& Engineering, 2020, 8(12): 4677-4692

10. Tahir M, Amin N S. Photocatalytic $\mathrm{CO}_{2}$ reduction and kinetic study over $\mathrm{In} / \mathrm{TiO}_{2}$ nanoparticles supported microchannel monolith photoreactor. Applied Catalysis A, General, 2013, 467: 483-496

11. Thompson W A, Fernandez E S, Maroto-Valer M M. Probability Langmuir-Hinshelwood based $\mathrm{CO}_{2}$ photoreduction kinetic models. Chemical Engineering Journal, 2020, 384: 123356

12. Marczewski A W. Analysis of kinetic Langmuir model. Part I: integrated Langmuir equation (IKL): a new complete analytical solution of the Langmuir rate equation. Langmuir, 2010, 26(19): 15229-15238

13. Bloh J Z. A holistic approach to model the kinetics of photocatalytic reactions. Frontiers in Chemistry, 2019, 7: 128

14. Li H, Yi F, Li X, Gao X. Numerical modelling of mass transfer processes coupling with reaction for the design of the ozone oxidation treatment of wastewater. Frontiers of Chemical Science and Engineering, 2021, 15(3): 602-614

15. Chu F, Chen S, Li H, Yang L, Ola O, Maroto-Valer M M, Du X, Yang Y. Modeling photocatalytic conversion of carbon dioxide in bubbling twin reactor. Energy Conversion and Management, 2017, 
149: $514-525$

16. Chen H, Chu F, Yang L, Ola O, Du X, Yang Y. Enhanced photocatalytic reduction of carbon dioxide in optical fibre monolith reactor with transparent glass balls. Applied Energy, 2018, 230: $1403-1413$

17. Verbruggen S W, Lenaerts S, Denys S. Analytic versus CFD approach for kinetic modelling of gas phase photocatalysis. Chemical Engineering Journal, 2015, 262: 1-8

18. Olivo A, Thompson W A, Bay E R B, Ghedini E, Menegazzo F, Maroto-Valer M, Signoretto $M$. Investigation of process parameters assessment via design of experiments for $\mathrm{CO}_{2}$ photoreduction in two photoreactors. Journal of $\mathrm{CO}_{2}$ Utilization, 2020, 36: 25-32

19. Wang X, Tan X, Yu T. Kinetic study of ozone photocatalytic decomposition using a thin film of $\mathrm{TiO}_{2}$ coated on a glass plate and the CFD modelling approach. Industrial \& Engineering Chemistry Research, 2014, 53(19): 7902-7909

20. Kočí K, Obalová L, Šolcová L. Kinetic study of photocatalytic reduction of $\mathrm{CO}_{2}$ over $\mathrm{TiO}_{2}$. Chemical \& Process Engineering, 2010, 31: 395-407

21. Ji Y, Luo Y. Theoretical study on the mechanism of photoreduction of $\mathrm{CO}_{2}$ to $\mathrm{CH}_{4}$ on the anatase $\mathrm{TiO}_{2}(101)$ surface. ACS Catalysis, 2016, 6(3): 2018-2025

22. Campbell C T, Sellers J R V. Enthalpies and entropies of adsorption on well-defined oxide surfaces: experimental measurements. Chemical Reviews, 2013, 113(6): 4106-4135

23. Meng X, Yun N, Zhang Z. Recent advances in computational photocatalysis: a review. Canadian Journal of Chemical Engineering, 2019, 97(7): 1982-1998

24. Dilla M, Schlögl R, Strunk J. Photocatalytic $\mathrm{CO}_{2}$ reduction under continuous flow high-purity conditions: quantitative evaluation of $\mathrm{CH}_{4}$ formation in the steady-state. ChemCatChem, 2017, 9(4): 696704

25. Tseng I, Chang W, Wu J C S. Photoreduction of $\mathrm{CO}_{2}$ using sol-gel derived titania and titania-supported copper catalysts. Applied Catalysis B: Environmental, 2002, 37(1): 34-48

26. Giammar D E, Maus C J, Xie L. Effects of particle size and crystalline phase on lead adsorption to titanium dioxide nanoparticles. Environmental Engineering Science, 2007, 24(1): 85-95

27. Mao W, Wilde M, Ogura S, Chen J, Fukutani K, Matsuzaki H, Terai $\mathrm{T}$. Hydrogen-accelerated phase transition and diffusion in $\mathrm{TiO}_{2}$ thin films. Journal of Physical Chemistry C, 2018, 122(40): 2302623033

28. Tan L L, Ong W J, Chai S P, Mohamed A R. Photocatalytic reduction of $\mathrm{CO}_{2}$ with $\mathrm{H}_{2} \mathrm{O}$ over graphene oxide-supported oxygenrich $\mathrm{TiO}_{2}$ hybrid photocatalyst under visible light irradiation: process and kinetic studies. Chemical Engineering Journal, 2017, 308: 248-255

29. Lopes F V S, Grande C A, Ribeiro A M, Loureiro J M, Evaggelos O, Nikolakis V, Rodrigues A E. Adsorption of $\mathrm{H}_{2}, \mathrm{CO}_{2}, \mathrm{CH}_{4}, \mathrm{CO}, \mathrm{N}_{2}$ and $\mathrm{H}_{2} \mathrm{O}$ in activated carbon and zeolite for hydrogen production. Separation Science and Technology, 2009, 44(5): 1045-1073

30. Bazan R E, Bastos-Neto M, Moeller A, Dreisbach F, Staudt R. Adsorption equilibria of $\mathrm{O}_{2}, \mathrm{Ar}, \mathrm{Kr}$, and $\mathrm{Xe}$ on activated carbon and zeolites: single component and mixture data. Adsorption, 2011, 17(2): 371-383

31. Delavari S, Amin N A S. Photocatalytic conversion of $\mathrm{CO}_{2}$ and $\mathrm{CH}_{4}$ over immobilized titanic nanoparticles coated on mesh optimization and kinetic study. Applied Energy, 2016, 162: 1171-1185

32. Lo C C, Hung C H, Yuan C S, Hung Y L. Parameter effects and reaction pathways of photoreduction of $\mathrm{CO}_{2}$ over $\mathrm{TiO}_{2} / \mathrm{SO}_{4}{ }^{2-}$ photocatalyst. Chinese Journal of Catalysis, 2007, 28(6): 528-534

33. Khalilzadeh A, Shariati A. Photoreduction of $\mathrm{CO}_{2}$ over heterogeneous modified $\mathrm{TiO}_{2}$ nanoparticles under visible light irradiation: synthesis, process and kinetic study. Solar Energy, 2018, 164: 251261

34. Sebastia-Saez D, Gu S, Ranganathan P, Papadikis K. Meso-scale CFD study of the pressure drop, liquid hold-up, interfacial area and mass transfer in structured packing materials. International Journal of Greenhouse Gas Control, 2015, 42: 388-399

35. Anpo M. Photocatalytic reduction of $\mathrm{CO}_{2}$ with $\mathrm{H}_{2} \mathrm{O}$ on highly dispersed Ti-oxide catalysts as a model of artificial photosynthesis. Journal of $\mathrm{CO}_{2}$ Utilization, 2013, 1: 8-17

36. Yin W, Wen B, Ge Q, Li X, Teobaldi G, Liu L. Activity and selectivity of $\mathrm{CO}_{2}$ photoreduction on catalytic materials. Dalton Transactions (Cambridge, England), 2020, 49(37): 12918-12928

37. Ola O, Maroto-Valer M M. Transition metal oxide based $\mathrm{TiO}_{2}$ nanoparticles for visible light induced $\mathrm{CO}_{2}$ photoreduction. Applied Catalysis A, General, 2015, 502: 114-121

38. Thompson $\mathrm{T} \mathrm{L}$, Yates $\mathrm{J} \mathrm{T} \mathrm{Jr}$. $\mathrm{TiO}_{2}$-based photocatalysis: surface defects, oxygen and charge transfer. Topics in Catalysis, 2005, 35(3-4): 197-210

39. Li D, Huang Y, Li S, Wang C, Li Y, Zhang X, Liu Y. Thermal coupled photoconductivity as a tool to understand the photothermal catalytic reduction of $\mathrm{CO}_{2}$. Chinese Journal of Catalysis, 2020, 41(1): $154-160$

40. Tan L, Xu S, Wang Z, Xu Y, Wang X, Hao X, Bai S, Ning C, Wang $\mathrm{Y}$, Zhang W, et al. Highly selective photoreduction of $\mathrm{CO}_{2}$ with suppressing $\mathrm{H}_{2}$ evolution over monolayered double hydroxide under irradiation above $600 \mathrm{~nm}$. Angewandte Chemie, 2019, 131(34): 11986-11993

41. Kohno Y, Hayashi H, Takenaka S, Tanaka T, Funabiki T, Yoshida S. Photo-enhanced reduction of carbon dioxide with hydrogen over $\mathrm{Rh} / \mathrm{TiO}_{2}$. Journal of Photochemistry and Photobiology A Chemistry, 1999, 126(1-3): 117-123

42. Zhou W, Guo J, Shen S, Pan J, Tang J, Chen L, Au C, Yin S. Progress in photoelectrocatalytic reduction of carbon dioxide. Acta Physica Sinica, 2020, 36(3): 1906048 (in Chinese)

43. Xie F, Chen R, Zhu X, Liao Q, Ye D, Zhang B, Yu Y, Li J.CO utilization: direct power generation by a coupled system that integrates photocatalytic reduction of $\mathrm{CO}_{2}$ with photocatalytic fuel cell. Journal of $\mathrm{CO}_{2}$ Utilization, 2019, 32: 31-36

44. Chen M, Wu J, Lu C, Luo X, Huang Y, Jin B, Guo H, Zhang X, Argyle M, Liang Z. Photoreduction of $\mathrm{CO}_{2}$ in the presence of $\mathrm{CH}_{4}$ over g- $\mathrm{C}_{3} \mathrm{~N}_{4}$ modified with $\mathrm{TiO}_{2}$ nanoparticles at room temperature. Green Energy \& Environment, 2021, in press 